Earth Interactions - Volume 23 (2019) • Paper No. 1 • Page 1

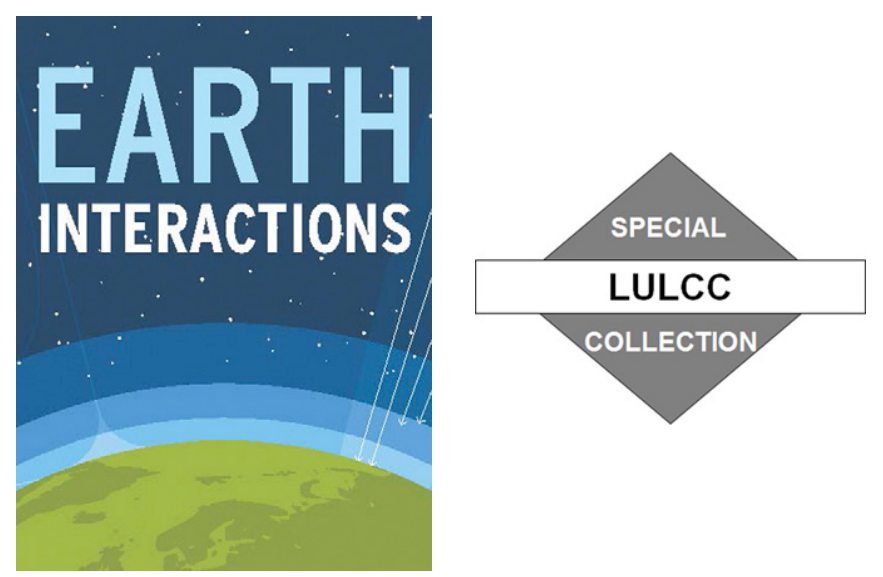

(C) 2019 American Meteorological Society. For information regarding reuse of this content and general copyright information, consult the AMS Copyright Policy (www.ametsoc.org/PUBSReuseLicenses).

\title{
Climate Impacts from Afforestation and Deforestation in Europe
}

\section{G. Strandberg ${ }^{\mathrm{a}, \mathrm{c}}$ and E. Kjellström ${ }^{\mathrm{b}}$}

Rossby Centre, Swedish Meteorological and Hydrological Institute, Norrköping, and Department of Meteorology and Bolin Centre for Climate Research, Stockholm University, Stockholm, Sweden

Received 29 November 2017; in final form 28 July 2018

\begin{abstract}
Changes in vegetation are known to have an impact on climate via biogeophysical effects such as changes in albedo and heat fluxes. Here, the effects of maximum afforestation and deforestation are studied over Europe. This is done by comparing three regional climate model simulations-one with presentday vegetation, one with maximum afforestation, and one with maximum deforestation. In general, afforestation leads to more evapotranspiration (ET), which leads to decreased near-surface temperature, whereas deforestation leads to less ET, which leads to increased temperature. There are exceptions, mainly in regions with little water available for ET. In such regions, changes in albedo are relatively more important for temperature. The simulated biogeophysical effect on seasonal mean temperature varies between $0.5^{\circ}$ and $3^{\circ} \mathrm{C}$ across Europe. The effect on minimum and maximum temperature is larger than that on mean temperature. Increased (decreased) mean temperature is associated with an even larger increase (decrease) in maximum summer (minimum winter) temperature. The effect on precipitation is found to be small. Two additional simulations in which vegetation is changed in
\end{abstract}

${ }^{\mathrm{a}}$ ORCID ID: 0000-0003-2689-9360.

${ }^{\mathrm{b}}$ ORCID ID: 0000-0002-6495-1038.

${ }^{\mathrm{c}}$ Corresponding author: Gustav Strandberg, gustav.strandberg@smhi.se

DOI: 10.1175/EI-D-17-0033.1 
Earth Interactions - Volume 23 (2019) - Paper No. 1 • Page 2

only one-half of the domain were also performed. These simulations show that the climatic effects from changed vegetation in Europe are local. The results imply that vegetation changes have had, and will have, a significant impact on local climate in Europe; the climatic response is comparable to climate change under RCP2.6. Therefore, effects from vegetation change should be taken into account when simulating past, present, and future climate for this region. The results also imply that vegetation changes could be used to mitigate local climate change.

KEYWORDS: Europe; Atmosphere-land interaction; Climate sensitivity; Feedback

\section{Introduction}

The land surface and its vegetation are part of the climate system; manmade and natural changes in the land cover can potentially have an impact on climate. Land cover influences climate in two ways: via biogeochemical exchanges-in particular, carbon dioxide $\left(\mathrm{CO}_{2}\right)$ - with the atmosphere and via biogeophysical properties that influence energy balance and exchange at the land surface (e.g., Pielke et al. 1998; Findell et al. 2007). Biogeochemical changes occur because changes in land cover also change the chemical composition of the atmosphere; for example, a growing forest binds $\mathrm{CO}_{2}$ and reduces the amount of $\mathrm{CO}_{2}$ in the atmosphere. Although there is still a large spread among global climate models in projections of future climate, the relationship between greenhouse gases and climate change is relatively well known (Cubasch et al. 2013). This means that the biogeochemical effects could be associated with a quantitative estimate, given changes in land cover and vegetation. Biogeochemical feedbacks from regional land-cover changes have been discussed in the context of global climate change in several studies (e.g., Carter et al. 2007; Arneth et al. 2010), where it is found that the biogeochemical feedback is too big to be ignored in climate change studies. Biogeophysical effects occur due to changes in the physical properties of the land surface, such as changes in albedo, soil properties, and roughness. The biogeophysical effects include changes in radiation, evapotranspiration, and surface heat fluxes. These effects are likely to act locally, whereas biogeochemical effects are spread globally via relatively fast mixing in the atmosphere. Although we have a general understanding of the biogeophysical processes operating at continental to regional scales, it is difficult to exactly quantify such processes (Levis 2010; Davin et al. 2014).

Global studies on present and future climate come to the conclusion that the albedo effect gives colder temperature as a consequence of deforestation but that this cooling effect is much smaller than the warming effect from greenhouse gas forcing (e.g., Brovkin et al. 2006; Bala et al. 2007; Betts et al. 2007; Forster et al. 2007; Teuling et al. 2010; Brovkin et al. 2013). Other experimental climate model studies with prescribed deforestation in large parts of the globe show a similar cooling effect on global mean temperature (Kleidon et al. 2000). Some studies have also shown regional effects of deforestation on climate, but the results from changing heat fluxes are described as ambiguous (Pitman et al. 2009) or hard to evaluate (Goosse et al. 2012). Biogeophysical effects work on local scales, and the response in climate can vary significantly between regions; even the sign in temperature and precipitation response depends on local/regional characteristics such as length of snow season, amount of water available for evapotranspiration, and time of year (Wramneby et al. 2010; Strandberg et al. 2014; Alexandru and 
Earth Interactions - Volume 23 (2019) • Paper No. 1 • Page 3

Sushama 2016). Global climate models involve the whole climate system; they include global budgets of $\mathrm{CO}_{2}$, which means that they can describe biogeochemical effects. However, due to the coarse horizontal resolution generally used, global climate models cannot resolve biogeophysical effects at regional to local scales (e.g., Findell et al. 2007, 2009; Avila et al. 2012; Christidis et al. 2013; Myhre et al. 2013).

The higher resolution in the regional climate models (RCMs) enables studies of local effects. RCMs improve the representation of regional-scale climate features (e.g., Rummukainen 2010). For future climates, the effects of afforestation have been studied with RCMs in Europe (e.g., Wramneby et al. 2010; Gálos et al. 2012), North America (e.g., Alexandru and Sushama 2016), Africa (e.g., Wu et al. 2016), and South America (e.g., Wu et al. 2017). The main finding is that the climate mitigation benefits of afforestation (due to $\mathrm{CO}_{2}$ uptake from the atmosphere) may be offset to some extent by counteracting biogeophysical forcing, but the exact balance between these two opposing forcings varies depending on the region considered. It is clear, however, that there are uncertainties in how the climatic response to vegetation changes varies between parts of Europe and parts of the year. Strandberg et al. (2014) shows in a paleo context that the climate forcing from regional land-cover changes in Europe may be strong, but the sign of the forcing varies according to local conditions. Studies with high resolution over Europe exist, but they are focusing on only one season (Zampieri and Lionello 2011; Stéfanon et al. 2014) and/or a limited part of Europe (Gálos et al. 2011; Zampieri and Lionello 2011; Gao et al. 2014; Stéfanon et al. 2014). The general conclusion from these studies is that afforestation leads to reduced temperatures in summer due to increased evapotranspiration.

Contrastingly, however, Zampieri and Lionello (2011) get colder summer climate when potential natural vegetation is replaced by crops, but as a result of higher evapotranspiration from crops. Gao et al. (2014) report that the effect in spring is opposite in Finland due to decreased albedo. Only Bathiany et al. (2010) studied both afforestation and deforestation, but that was on $3.75^{\circ}$ horizontal resolution. Their conclusion was that boreal afforestation warms the surface and deforestation cools the surface, due to albedo changes and despite counteracting changes in $\mathrm{CO}_{2}$. Still, detailed information about the effect of afforestation on winter climate as well as the effect of deforestation is missing. Studies of changes in the available water at the surface or in the soil show that such changes affect precipitation and circulation on the local/convective scale, but mostly the timing and location of precipitation rather than the total precipitation within a larger area (e.g., Roy et al. 2007; Quintanar and Mahmood 2012; Seneviratne et al. 2013; Winchester et al. 2017).

Europe has experienced substantial deforestation during the last 100-1000 years; within this time, the forest fraction has decreased from $100 \%$ to $30 \%$ in most parts of continental Europe (e.g., Kaplan et al. 2009; Klein Goldewijk et al. 2011). For different periods of the past, climate studies conducted with global models at a coarse spatial resolution suggest that the albedo effect is the dominating biogeophysical effect leading to a colder climate when deforestation occurs in the Northern Hemisphere (e.g., Jahn et al. 2005; Brovkin et al. 2006; Pitman et al. 2009; Pongratz et al. 2009; Goosse et al. 2012; He et al. 2014). Currently, afforestation is considered as a mitigation strategy by $\mathrm{CO}_{2}$ sequestration (Mykleby et al. 2017); despite that, the reduced radiative forcing from reduced $\mathrm{CO}_{2}$ in the atmosphere might locally be counteracted by biogeophysical positive forcing. 
Earth Interactions • Volume 23 (2019) • Paper No. 1 • Page 4

Biogeophysical impacts of land-cover changes are recognized to be an important driver of climate change on the global scale (e.g., Myhre et al. 2013) and even the fourth most important anthropogenic driver during the historical period (Andrews et al. 2017). This, together with the relatively wide climate gradients across Europe, makes it a suitable area to study the magnitude and size of biogeophysical forcing from changing forest cover. However, the climatic effects of afforestation are still not completely understood, especially in northern high-latitude regions where the snow albedo effect induces local cooling (Mykleby et al. 2017). Thus, there is a need for a comprehensive study of both afforestation and deforestation that distinguishes between seasons on European scale at a resolution that is high enough to resolve regional characteristics and responses.

\section{Aim}

This study aims to estimate the magnitude and size of biogeophysical forcing from changing vegetation in Europe. Globally the greenhouse gas forcing is of much greater importance, but on the local/regional scale the size of the biogeophysical forcing may be of equal size (e.g., Levis 2010; Wramneby et al. 2010). Furthermore, the sign of the response to biogeophysical forcing varies between regions due to local surface properties and climate context. The biogeophysical forcing is a potentially large forcing that is not well constrained in climate models. We aim to investigate the possible effects of maximum deforestation and afforestation as possible mitigation strategies for the future. To this end, we simulated and compared two scenarios for land-cover changes: 1) maximum afforestation (potential vegetation) and 2) maximum deforestation. Both simulations are compared with a control simulation representing present-day conditions. Effects of each scenario on mean climate and extreme climate were investigated. It is, of course, not realistic to think that Europe will be completely deforested/afforested all at the same time. This approach enables us, however, to study the potential maximum effect of deforestation/afforestation. Instead of just selecting one region in Europe, by changing the land cover in the whole model domain we can identify the regions with large/small response and how the response varies within Europe. Also, this study investigates how these responses vary over the year.

To investigate whether land-cover changes have any nonlocal effects, we perform two additional simulations in which afforestation and deforestation are only done in the western part of the domain (west of $15^{\circ} \mathrm{E}$ ). The western part of the domain is more likely to affect the eastern part than the other way around since the prevailing winds are westerlies (e.g., Keys et al. 2016). In these experiments, climatic change in the eastern part of the domain is a nonlocal effect of vegetation changes in the western part.

\section{Methods}

\subsection{The regional climate model RCA4}

The Rossby Centre regional climate model RCA4 (Strandberg et al. 2015; Kjellström et al. 2016) is used to perform the climate simulations. RCA4 and its predecessors, RCA, RCA2, and RCA3, have been extensively used and evaluated 
in studies of present and future climate (e.g., Rummukainen et al. 2001; Räisänen et al. 2004; Kjellström et al. 2011; Nikulin et al. 2011). Also, RCA3 has been used in palaeoclimatological applications for downscaling global model results for the last millennium (Graham et al. 2009; Schimanke et al. 2012), for parts of the Marine Isotope Stage 3 (Kjellström et al. 2010), for the Last Glacial Maximum (Strandberg et al. 2011), and for $200 \mathrm{yr}$ before present (BP) and $6000 \mathrm{yr}$ BP (Strandberg et al. 2014). RCA4 is run on a horizontal grid spacing of $0.44^{\circ}$ (corresponding to approximately $50 \mathrm{~km}$ ) over Europe with 24 vertical levels and a time step of 30 min. Every $6 \mathrm{~h}$, RCA4 reads surface pressure, humidity, temperature, and wind from ERA-Interim (Dee et al. 2011) along the lateral boundaries of the model domain, and sea surface temperature and sea ice extent within the model domain.

Surface albedo in RCA4 is a function of leaf area index (LAI). LAI is calculated as a function of the soil temperature with a lower limit set to 0.4 and upper limits to 2.3 (forest free) and 4.0 (deciduous forest). If deep soil moisture reduces to the wilting point, the LAI is set to its lower limit. LAI in coniferous forests is set constant to 4.0 regardless of soil moisture. For snow in forest-free areas, RCA4 has a prognostic albedo that varies between 0.6 and 0.85 ; the albedo decreases as snow ages. For snow-covered land areas in forest regions, the albedo is set constant to 0.2. The snow-free albedo is set to 0.15 and 0.28 for forest and forest-free areas, respectively (Samuelsson et al. 2011). The root depth varies from around $1.5 \mathrm{~m}$ for open land to $2 \mathrm{~m}$ for forest (Champeaux et al. 2005). Surface resistance depends on a vegetationdependent minimum surface resistance, LAI, photosynthetically active radiation, water stress, vapor pressure deficit, air temperature, and soil temperature. The most important differences in surface resistance between forest and open land are the effect of water stress, which depends on root depth, and the effect of vapor deficit; open land resistance is independent of vapor deficit (Jarvis et al. 1976).

To minimize model dependencies in the results, all RCA4 simulations have been driven by the ERA-Interim data. By using the same climate forcing in all simulations, the differences in results are only an effect of how vegetation and climate interact within RCA4. Every simulation starts with a 1-yr spin up; after that, the 30yr period 1981-2010 is simulated. For each simulation of a 30-yr period, we calculate the average of the nominal seasons winter [December-February (DJF)] and summer [June-August (JJA)]. In addition, cold and warm extremes are analyzed by investigating differences in monthly minimum value of daily minimum temperature (TNn) and monthly maximum of daily maximum temperature (TXx) and how they relate to the changes in mean temperature (cf. Kjellström 2004). For two selected summer months, the number of days with TXx above the 90th percentile of TXx (TX90P) is calculated. Percentiles are calculated empirically as the climatological value over the entire 30 -yr period. The results are shown as differences between the afforestation and deforestation simulations relative to the control simulation. The statistical significance for the difference between the simulations is determined by a Student's $t$ test based on daily data to see if the difference between two simulations is statistically significant. We choose a significance level of 0.05. Three different regions in Europe are studied in more detail; annual cycles for selected variables are shown for them as well. These regions are west continental Europe (WCE; $3.42^{\circ}-11.57^{\circ} \mathrm{E}, 47.08^{\circ}-51.38^{\circ} \mathrm{N}$ ), east continental Europe $\left(\mathrm{ECE} ; 18.00^{\circ}-29.50^{\circ} \mathrm{E}, 43.91^{\circ}-48.32^{\circ} \mathrm{N}\right)$, and the Iberian Peninsula $\left(\mathrm{IBP} ;-6.37^{\circ} \mathrm{E}-0^{\circ}, 37.53^{\circ}-42.64^{\circ} \mathrm{N}\right)$. 


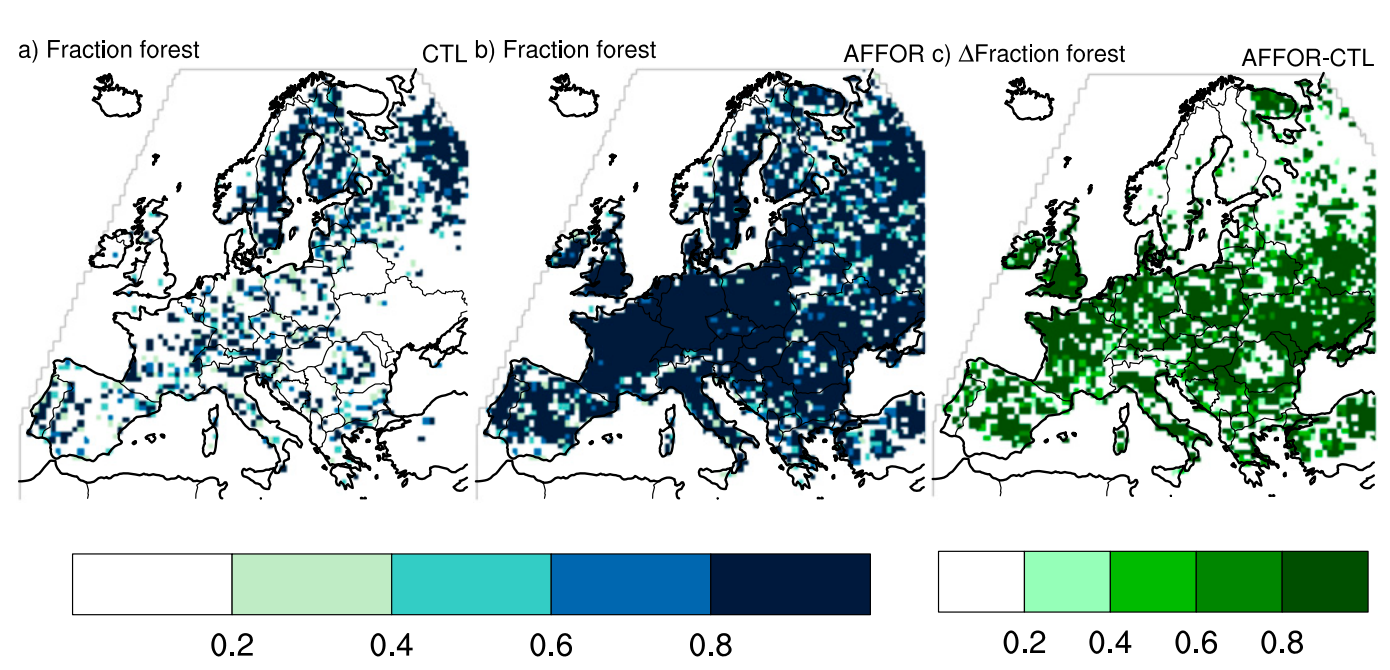

Figure 1. (a) Fraction of forest in the CTL and (b) AFFOR simulations; (c) the difference in fraction of forest between the AFFOR and CTL simulations.

\subsection{Vegetation}

For the control simulation (CTL), present-day land cover was used as defined in ECOCLIMAP (Champeaux et al. 2005; Figure 1a). In the afforestation simulation (AFFOR), a potential land cover is used following Strandberg et al. (2014), where the dynamic vegetation model LPJ-GUESS (Smith et al. 2001; Hickler et al. 2004, 2012) was used to simulate potential natural vegetation patterns consistent with the simulated climate in Europe. Here, potential vegetation means that vegetation is allowed to grow freely without human intervention under present-day climate conditions; after 300 years of spin up, we take the simulated vegetation as representative of CTL conditions. This results in a forest cover of $100 \%$ almost everywhere and is regarded as an extreme case for maximum forest cover. This could be seen as a proxy for prehistoric conditions in Europe (e.g., Trondman et al. 2015). In some regions (e.g., around the Mediterranean Sea), vegetation is limited by precipitation. In mountainous regions (e.g., Scotland, Scandinavian mountain range, parts of the Alps) the presence of trees may be restricted by low winter temperatures. Consequently, these regions are not fully forested in the case of potential vegetation (Figures 1b,c). In the deforestation simulation (DEFOR), all forests in the present land cover are replaced by grassland; in this case, there is no forest anywhere (not shown).

\section{Results}

\subsection{Albedo and evapotranspiration}

Forests have a lower albedo than open land, and consequently, afforestation leads to a reduction in albedo over almost all of Europe: from -0.4 in the east to close to zero in the west (Figures $2 \mathrm{a}, \mathrm{b}, 3 \mathrm{a}-\mathrm{c}$ ). The largest difference is seen in eastern Europe in winter. This is a region with a large increase in forest fraction and a long snow season. When open land (which is more readily covered by snow) is 


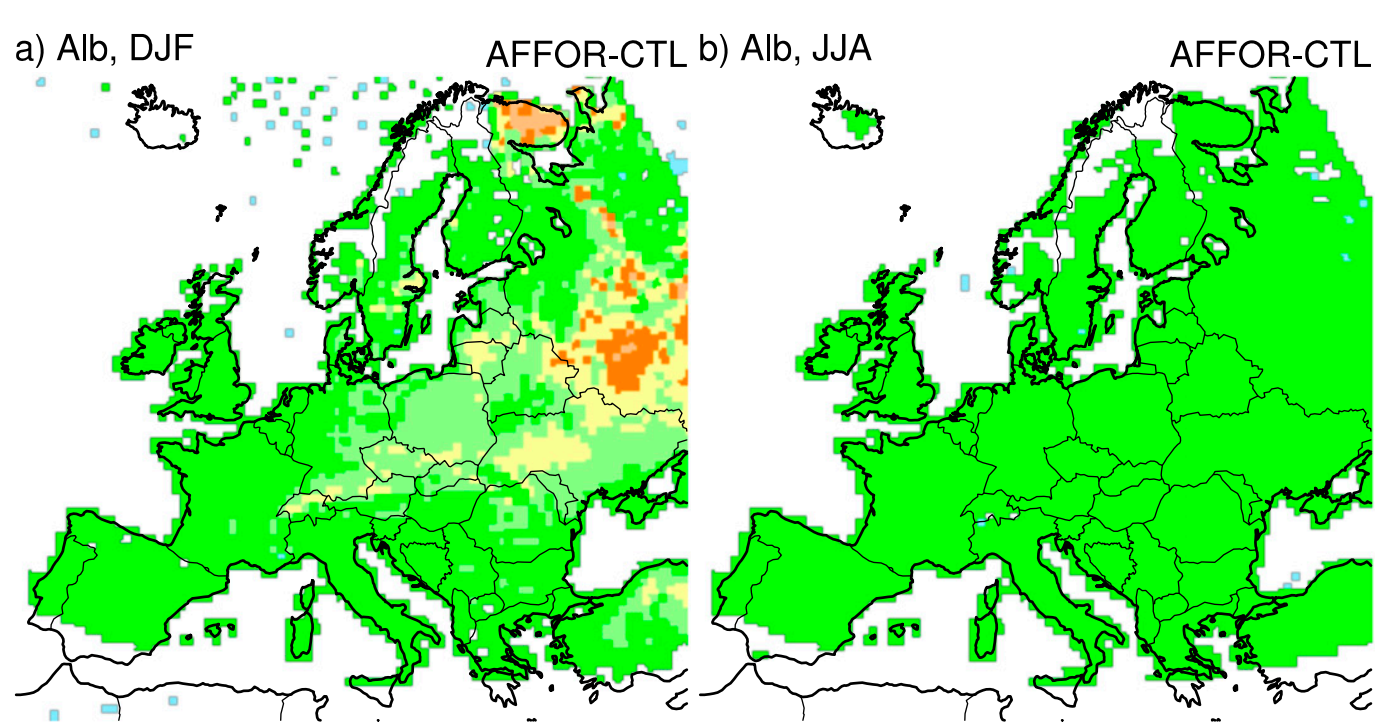

c) Alb, DJF DEFOR-CTL d) Alb, JJA

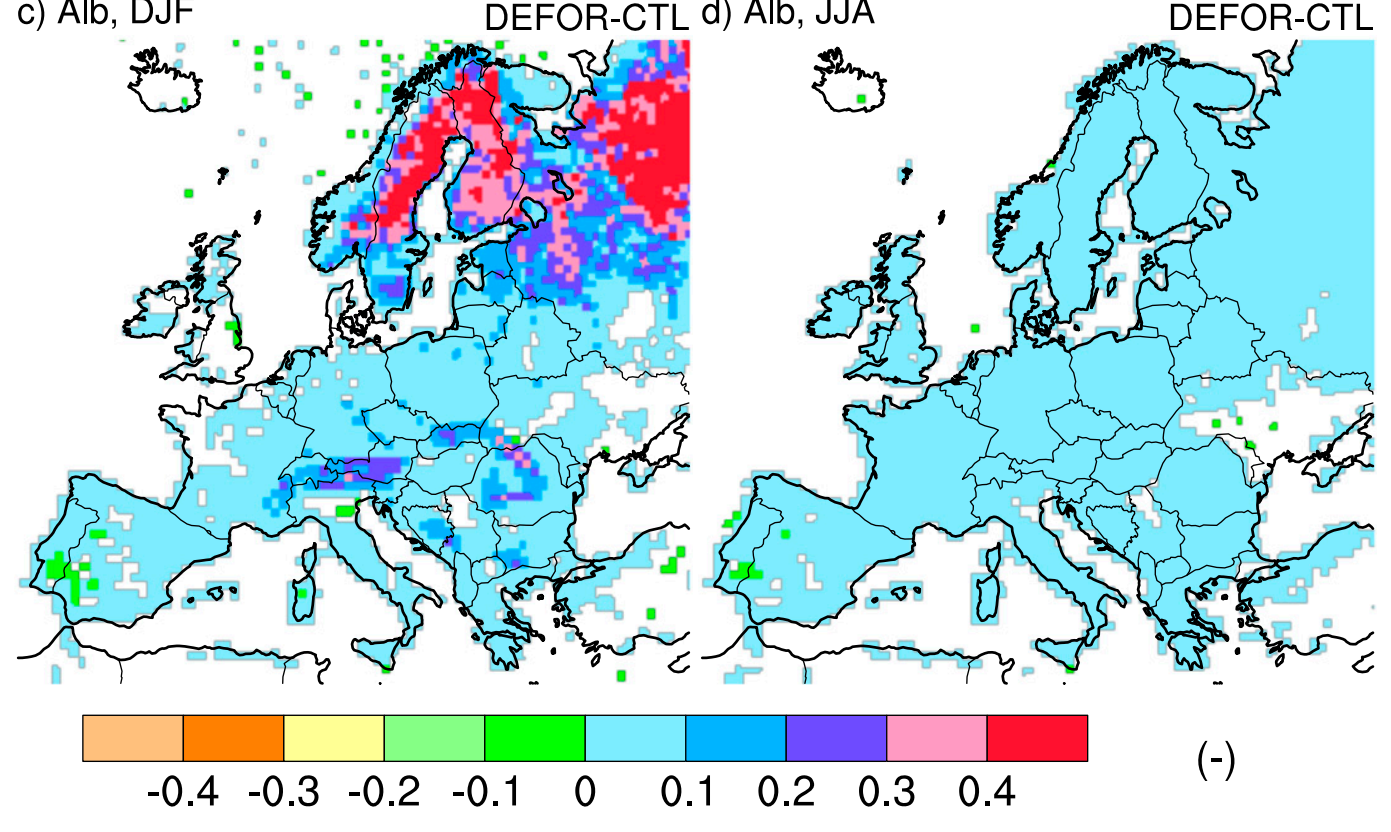

Figure 2. Difference in albedo (label "allb") (a),(b) between the AFFOR and CTL simulations and (c),(d) between the DEFOR and CTL simulations for (left) winter (DJF) and (right) summer (JJA). Grid points that do not show statistically significant differences are omitted.

replaced by forest, the change in albedo is larger than when open land is replaced by forest in a snow-free region. In summer, differences in albedo are much smaller. A comparison with Figure 4 shows that the largest differences in winter albedo to a strong degree correspond to changes in the length of the snow season rather than to changes in forest cover.

Evapotranspiration (ET) also changes with changing land cover. Here, we focus on differences in the summer season since ET is small in winter. Afforestation 
Earth Interactions - Volume 23 (2019) - Paper No. 1 • Page 8

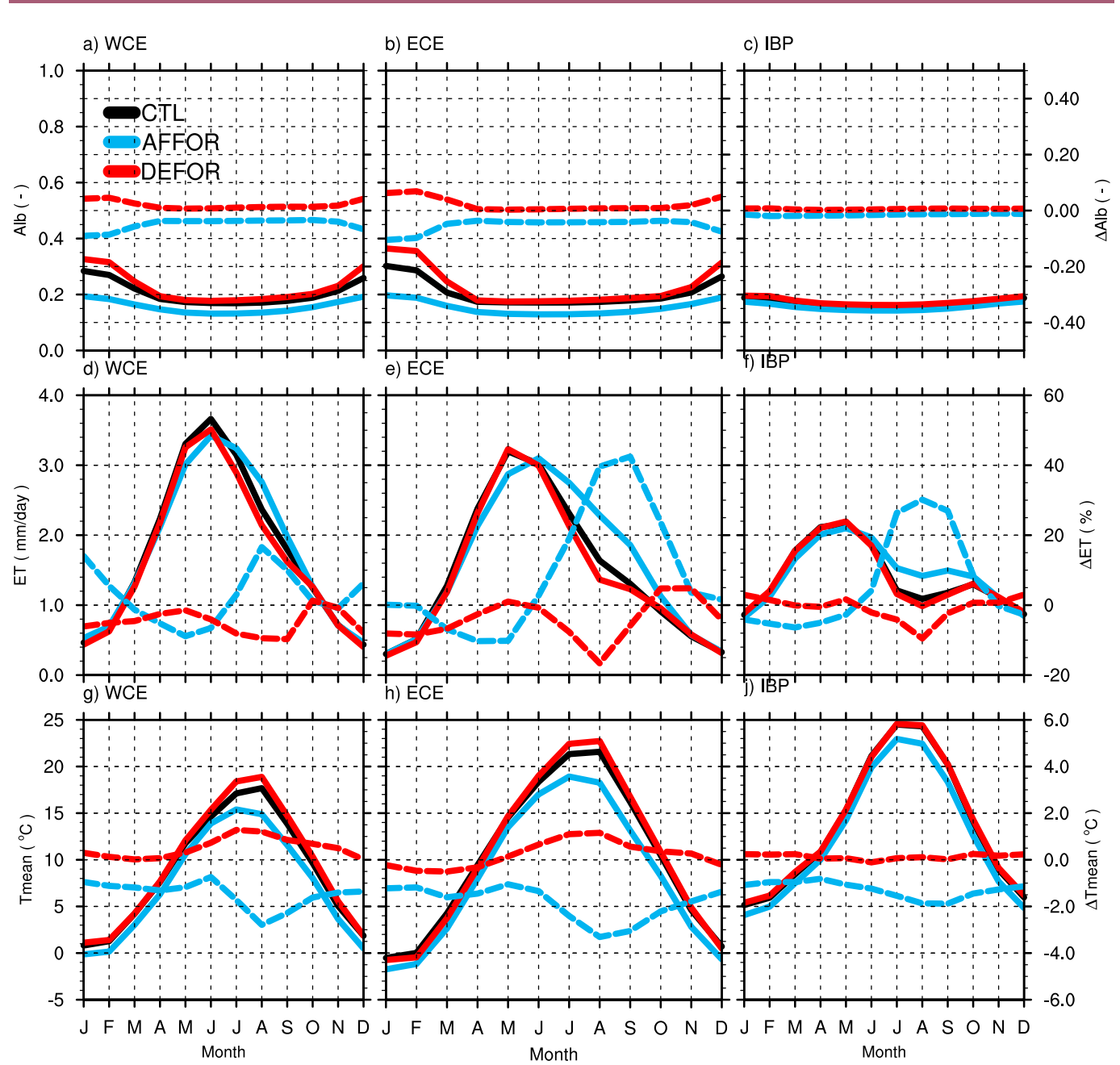

Figure 3. Annual cycles in the CTL (black lines), AFFOR (blue lines), and DEFOR (red lines) simulations: (a)-(c) albedo (alb), (d)-(f) evapotranspiration (ET, (g)-(j) temperature (Tmean) for (left) west central Europe, (center) east central Europe, and (right) the lberian Peninsula. Solid lines and the left-side $y$ axes show absolute values; dashed lines and the right-side $y$ axes show differences relative to CTL.

generally enables more ET (Figure 5a). Forests have higher LAI and larger root depth than open land. Since vegetation transpires water through leaf stomata, a higher LAI gives not only more water intercepted on the leaves, but also more transpiration, as long as water availability or temperature are not limiting factors. Furthermore, the larger root depth increases the ability to extract water from the ground. Most of southern Europe sees an increase of 25\%-35\%, while ET is relatively unchanged in northern Europe. However, comparing Figures 1 and 5 does not show a clear correspondence between changes in forest fraction and ET. The same change in forest fraction in southern and northern Europe does not give the same change in ET. The spatial pattern correlation between difference in forest 


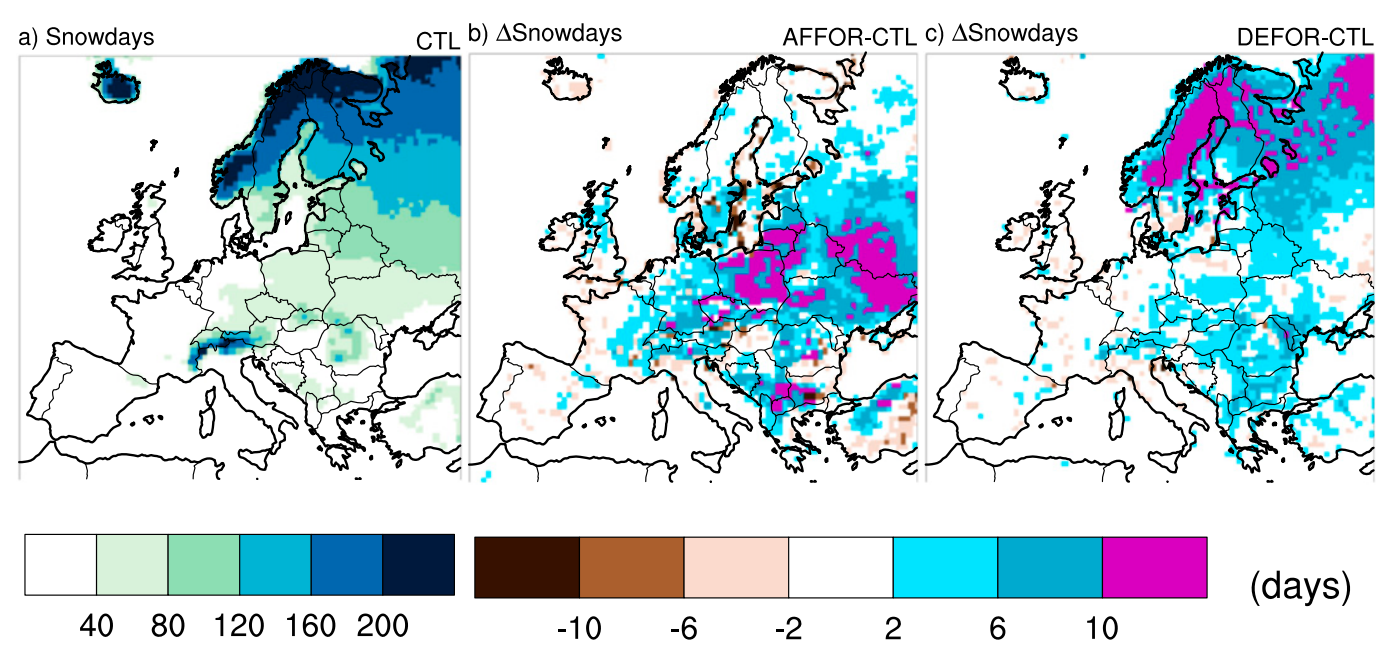

Figure 4. (a) Number of days with snow cover (days) in the CTL simulation, along with the difference in number of days with snow cover in the (b) AFFOR and (c) DEFOR simulations relative to CTL.

cover and difference in ET is 0.28 and 0.19 for AFFOR-CTL and DEFOR-CTL, respectively. Further, we note that a higher value of seasonal mean ET does not necessarily mean that the annual maximum ET is higher. In central and southern Europe, the AFFOR simulations give a longer period of high ET rather than a higher annual maximum. Compared to grasses, trees with long roots can utilize water from deeper soil layers, which prolongs the period of ET (e.g., Kelliher et al. 1993). The timing of the annual maximum ET is also delayed by about 1 month (Figures 3d-f).

The JJA albedo in DEFOR shows only small increases compared to CTL in most of Europe. In DJF, however, it is considerably higher (0.2-0.5) in Scandinavia and northwestern Russia (Figures 2c,d) due to the interaction between surface characteristics and the extensive snow cover present in these regions. ET in summer is lower in DEFOR in large parts of Europe, although the difference is not always statistically significant (Figures $3 \mathrm{~d}-\mathrm{f}, 5 \mathrm{~b}$ ). The largest differences in ET coincide with the largest differences in fraction of forest (e.g., a reduction of $20 \%-35 \%$ in Scandinavia and a reduction of around $20 \%$ in scattered parts of south-central Europe). ET increases with around $20 \%$ over the Baltic Sea in summer. This may seem counterintuitive, but when the warmer and drier air from the surroundings (cf. Figure 6d) comes in contact with the sea, it favors increased ET over sea. Similar, although less significant, increases are also seen off other coastal areas.

Despite similar differences in forest fraction, the responses in ET in the three regions WCE, ECE, and IBP are different (Figures 3d-f). In WCE, the climate is to a large degree governed by the large-scale circulation and the weather systems coming from the Atlantic, which makes the climate in this region less sensitive to land-cover changes. Here, the difference in ET is within $\pm 10 \%$ for most of the year in both simulations (Figure $3 \mathrm{~d}$ ). ECE is a region less influenced by the North 


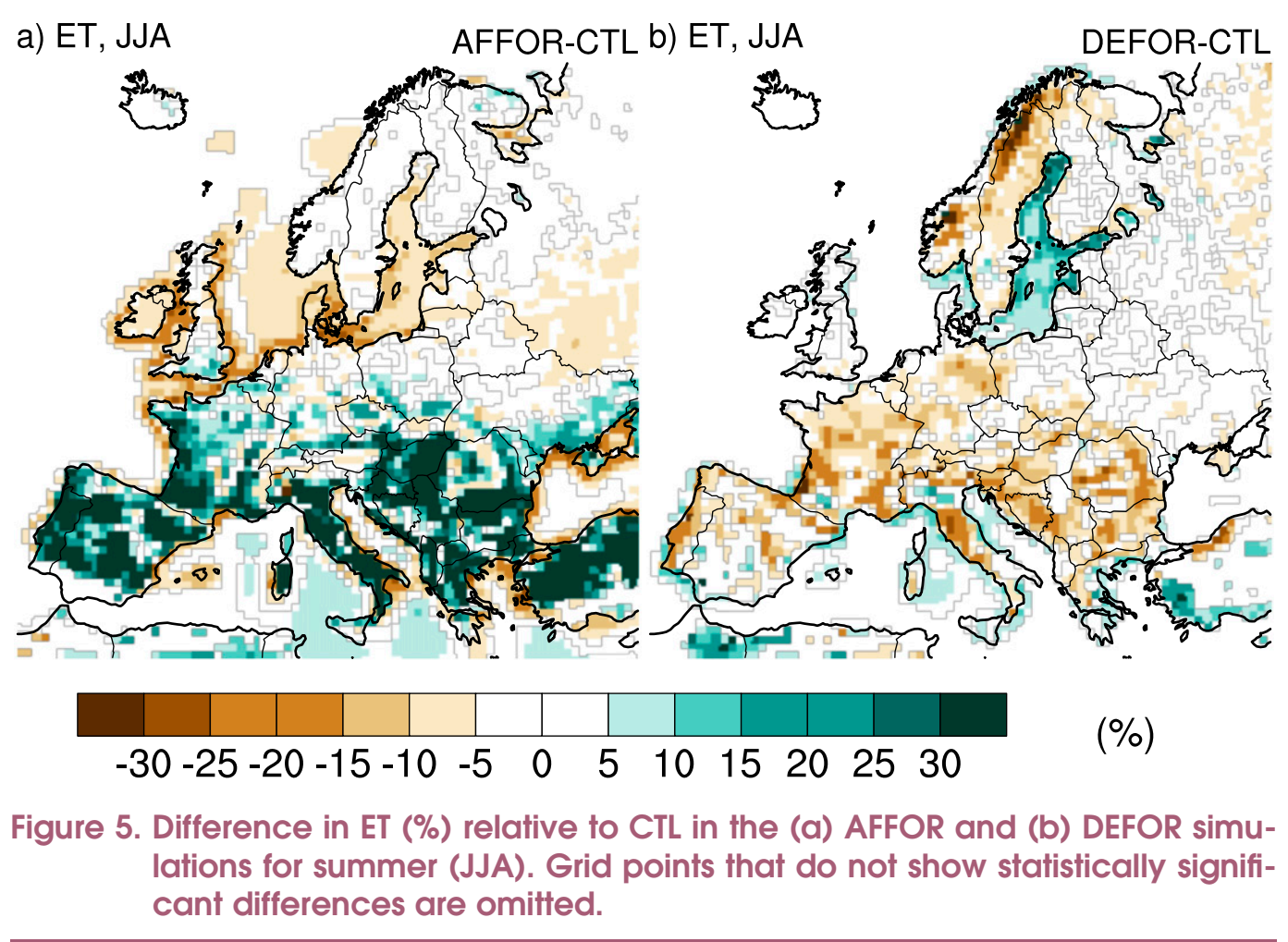

Atlantic and with water available for ET. Increased forest fraction in AFFOR enables the season of high ET to expand into the late summer; ET is up to $40 \%$ larger in August and September relative to CTL (Figure 3e). IBP is a dry region, where the available soil moisture is used already in the spring; hence, ET is not sensitive to further deforestation since there is not much water to evaporate or transpire in any case (Figure 3f). However, a substantial increase in forest cover on the Iberian Peninsula as in AFFOR results in less significant drying in late winter and spring, with more water available for ET.

\subsection{Seasonal mean temperatures}

The winter temperature (Tmean) in AFFOR is significantly colder by up to $-2^{\circ} \mathrm{C}$ in central and southern Europe (i.e., the areas affected by afforestation; Figure 6a). This is not explained by albedo changes (Figure 2) since decreased albedo should lead to higher temperature. Also, ET is not responsible, because it is low in winter and changes in it are small (e.g., Figure $6 \mathrm{~b}$ for ET in the IBP). The lower temperatures may instead be explained by changes in the atmospheric circulation. Because of increased roughness, the low pressure systems in AFFOR lose their energy earlier because of increased friction over land, compared to CTL and DEFOR, which in turn suggests a climate with less cyclonic activity in central Europe. This effect would be strongest in winter (when most of the cyclones occur). In winter, we note a rising of the mean geopotential height at $500 \mathrm{hPa}$ (GPH500) with around $100 \mathrm{~m}$ in an area centered on the Baltic states and a weakening of the $u$ wind at $850 \mathrm{hPa}$ in central and 
a) Tmean, DJF
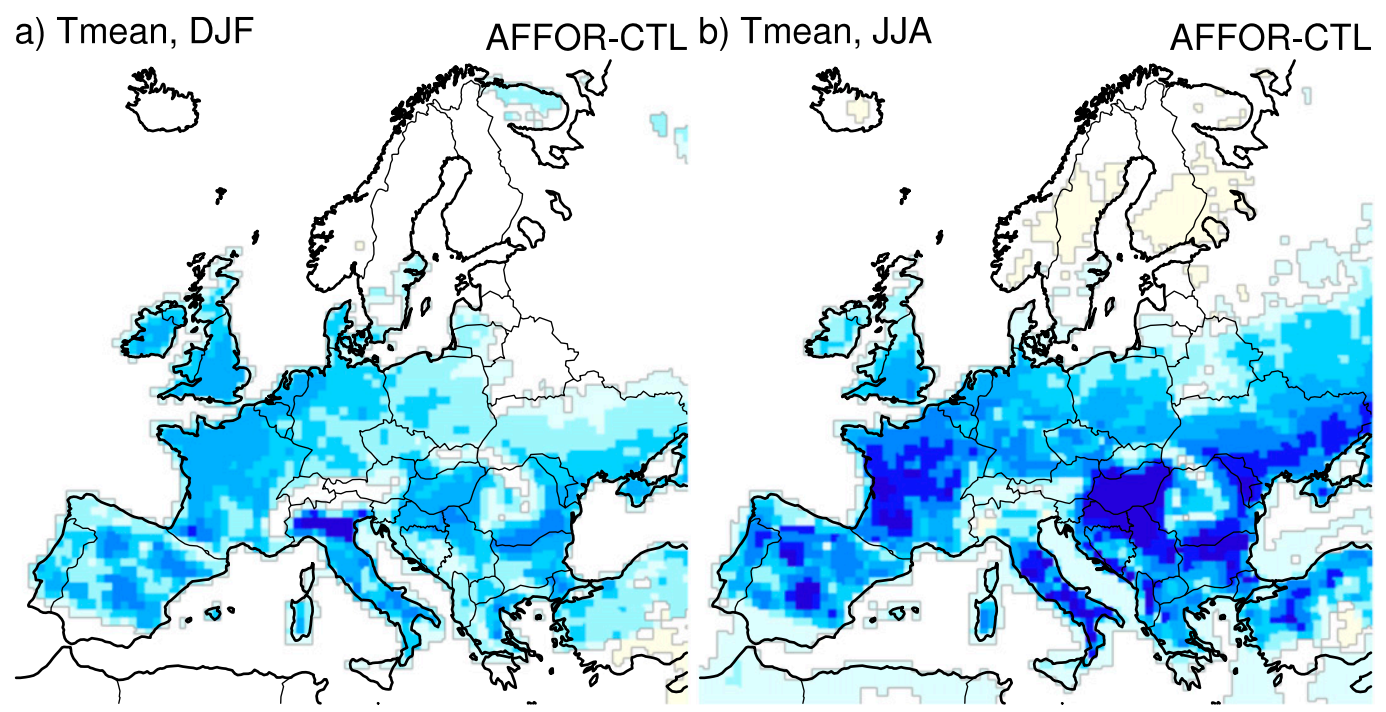

c) Tmean, DJF

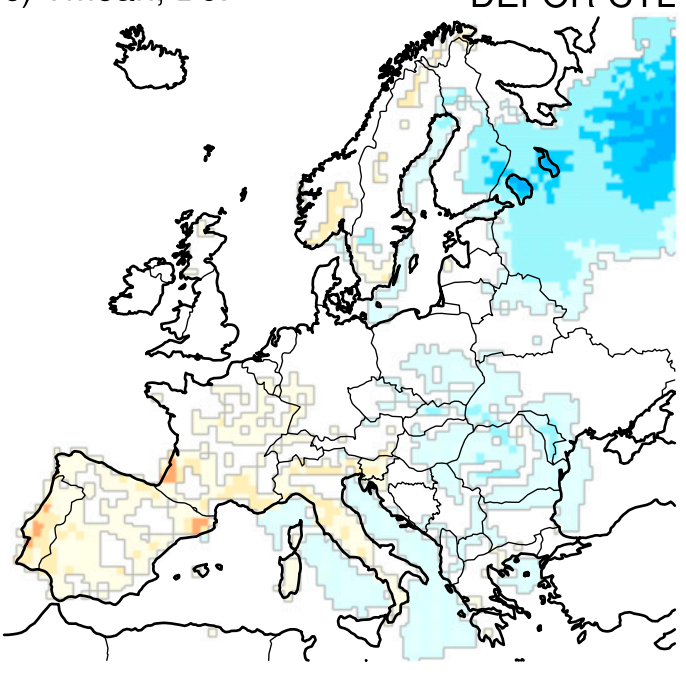

d) Tmean, JJA
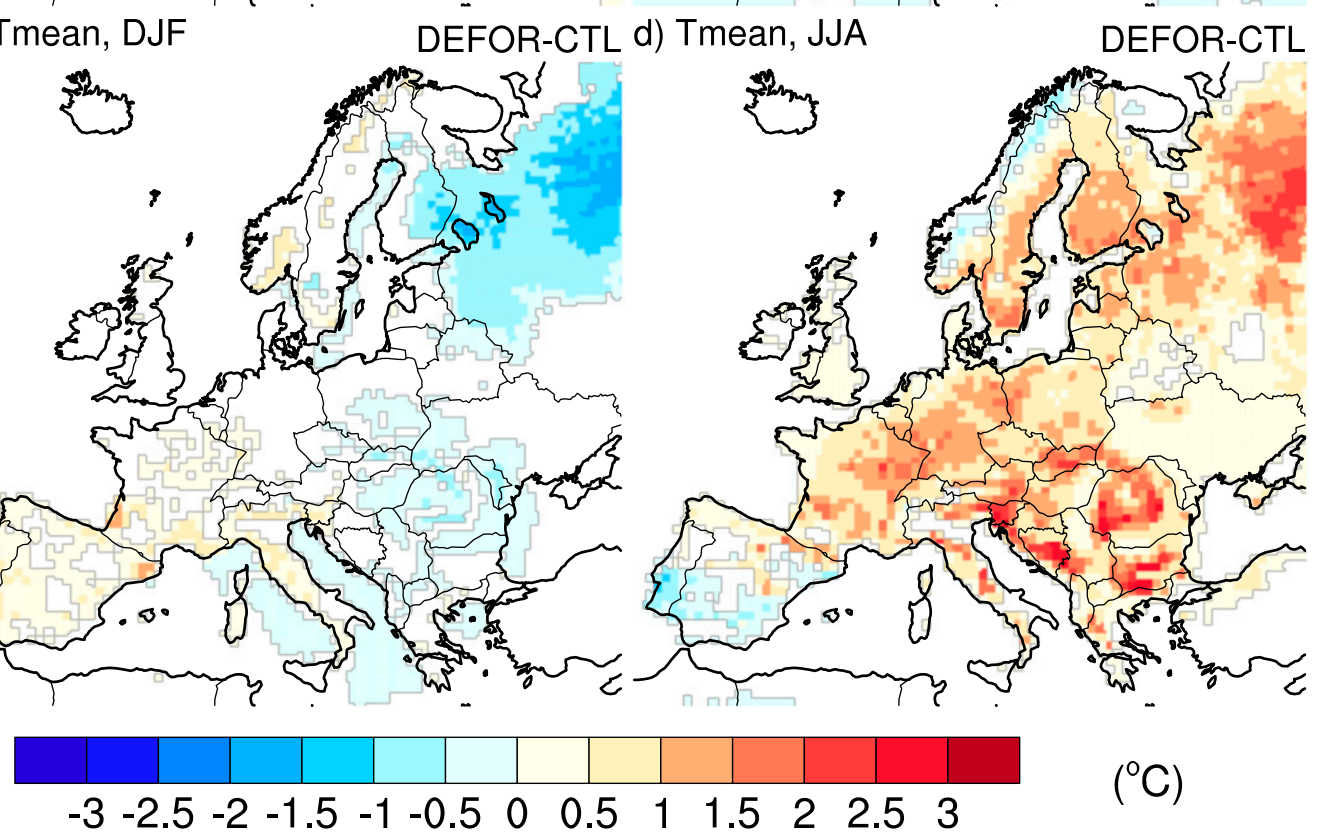

$\left({ }^{\circ} \mathrm{C}\right)$

Figure 6. Difference in mean near-surface temperature (Tmean; $\left.{ }^{\circ} \mathrm{C}\right)(\mathrm{a})$, (b) between the AFFOR and CTL simulations and (c),(d) between the DEFOR and CTL simulations for (left) winter (DJF) and (right) summer (JJA). Grid points that do not show statistically significant differences are omitted.

southeastern Europe (Figures 7a,c), all of which could contribute to the lower temperatures. A similar but slightly northward-shifted pattern is shown in summer with the addition of a lowering of the GPH500 of around $80 \mathrm{~m}$ in southern Europe (Figures 7b,d). This is a thermal effect caused by the cooler lower atmosphere (Mcllveen 1992) over southern Europe that is caused by increased ET (cf. Figure 5). Another potential explanation is that an initial increase in ET leads to decreased Tmean; together, this could lead to a lowering of the condensation level, which is 


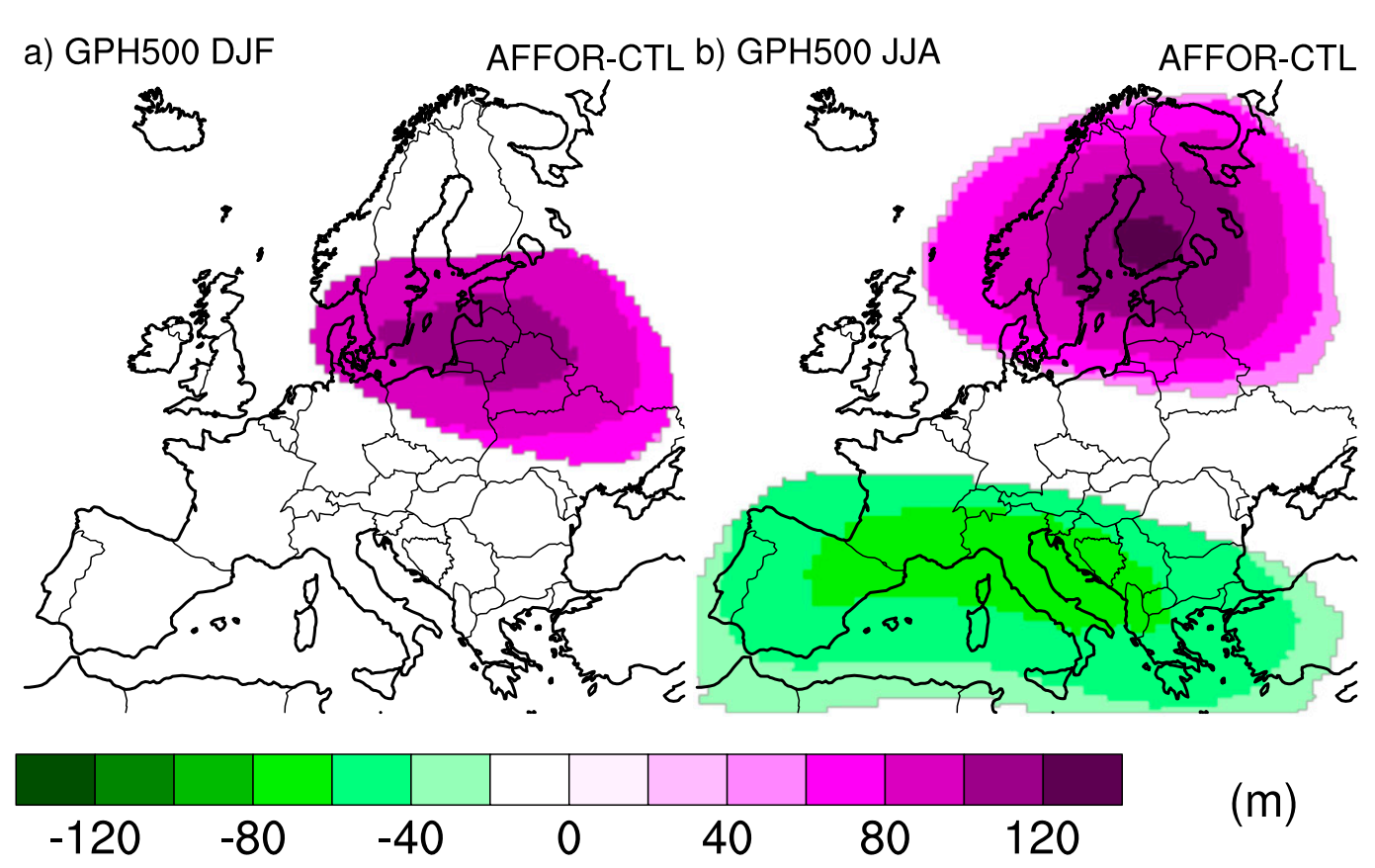

c) U-wind850 DJF AFFOR-CTL d) U-wind850 JJA AFFOR-CTL
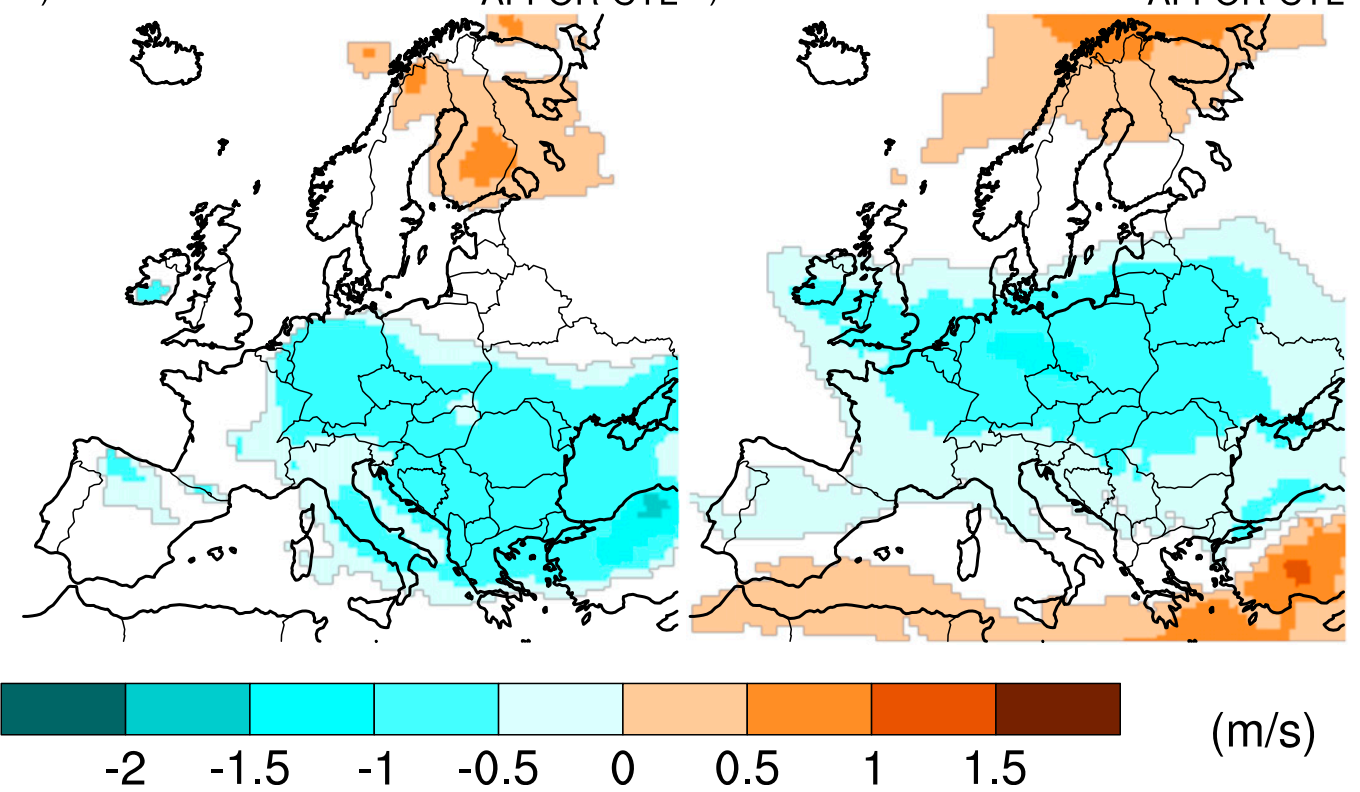

$(\mathrm{m} / \mathrm{s})$

Figure 7. Difference in (a),(b) geopotential height (GPH500; $\mathrm{m}$ ) and (c), (d) u wind at $850 \mathrm{hPa}\left(\mathrm{U}\right.$-wind850; $\mathrm{m} \mathrm{s}^{-1}$ ) between the AFFOR and CTL simulations in the (left) winter (DJF) and (right) summer (JJA). Grid points that do not show statistically significant differences are omitted. 
Earth Interactions • Volume 23 (2019) • Paper No. 1 • Page 13

beneficial for cloud formation (Pinto et al. 2009). These cause-effect chains are, however, far from clear, and the relationship among afforestation, deforestation, storm tracks, and cloud formation could be investigated further.

In winter, temperature differences due to deforestation are generally relatively small. Small positive temperature (Tmean) differences of $0.5^{\circ}-1^{\circ} \mathrm{C}$ in DEFOR relative to CTL are seen over parts of the Iberian Peninsula (Figure 6c). These changes are connected to the lower albedo. The large difference in winter albedo in northern Europe and over the Alps does not have an impact on winter Tmean. This is due to the small solar radiation in winter at these latitudes. The effect is stronger in spring; when there is more sunlight and also remaining snow on the ground, high albedo leads to significantly lower temperature in Scandinavia (not shown). In summer, Tmean is $1^{\circ}-3^{\circ} \mathrm{C}$ higher in the parts of Europe where deforestation takes place as an effect of the reduced ET (Figure 6d). Areas without forests in the control climate, however, see only a little difference. This includes parts of the Iberian Peninsula, Italy, coastal areas in northwestern Europe including the British Isles, Denmark, large parts of Norway, and the Kola Peninsula. Furthermore, parts of the Iberian Peninsula are already dry in the control experiment, and ET cannot be much lower in summer even if there is some local deforestation (Figure 3f). Under these conditions, the higher albedo even leads to locally colder temperature, down to a difference of $-1^{\circ} \mathrm{C}$, which is most pronounced in southern Portugal. This can be compared with the differences in Tmean in WCE and ECE, where the same difference in forest fraction gives different responses in Tmean. This is coupled to differences in ET as well as to changes in the large-scale circulation (see section 4.1).

\subsection{Extreme temperatures}

The monthly minimum of daily minimum temperature (TNn) in winter does not change in the same way as winter Tmean in AFFOR. TNn increases by up to $6^{\circ} \mathrm{C}$ in eastern Europe, as compared with a decrease of around $1{ }^{\circ} \mathrm{C}$ in Tmean (Figure 8a). Less-pronounced cold conditions in this area may seem counterintuitive, given the longer snow season (cf. Figure 4). This apparent discrepancy can be explained by changes in the cloud cover. The outgoing longwave radiation is decreased in this region as a result of increased cloud cover (not shown), leading to less-cold extreme conditions. It is interesting to compare with winter Tmean, which is colder in AFFOR than in CTL (cf. Figure 6). Cold extremes (TNn) mostly occur during night when increased cloud cover (reemitting longwave radiation back toward the surface) leads to increased $\mathrm{TNn}$, whereas increased cloud cover during daytime (reflecting incoming shortwave radiation back to space) acts to reduce warm extremes.

The summertime monthly maximum of daily maximum temperatures (TXx) differs in a way that is similar to that of daily mean temperatures between the different experiments, with strong differences in southern and central Europe. The difference in TXx is more pronounced than the difference in Tmean, however. TXX is reduced by $6^{\circ}-10^{\circ} \mathrm{C}$ in an area reaching from France and the southern parts of the British Isles eastward through Europe to areas north of the Black Sea (Figure 8b). Summer is the season with largest ET; therefore, changes in vegetation will impact ET the most in summer and even more so on the warmest days. The difference between Tmean and TXx is decreased, indicating that the summer temperature is 
a) TNn, DJF



b) TXX, JJA
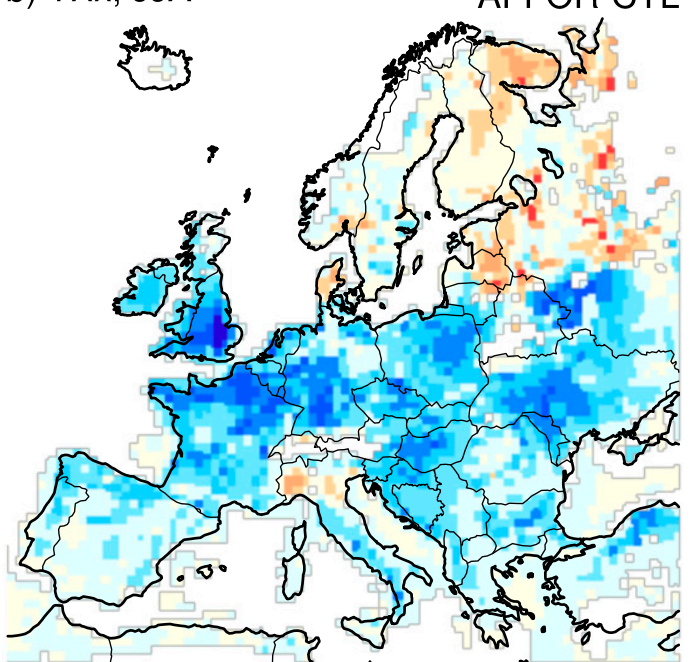

c) TNn, DJF

DEFOR-CTL d) TXX, JJA

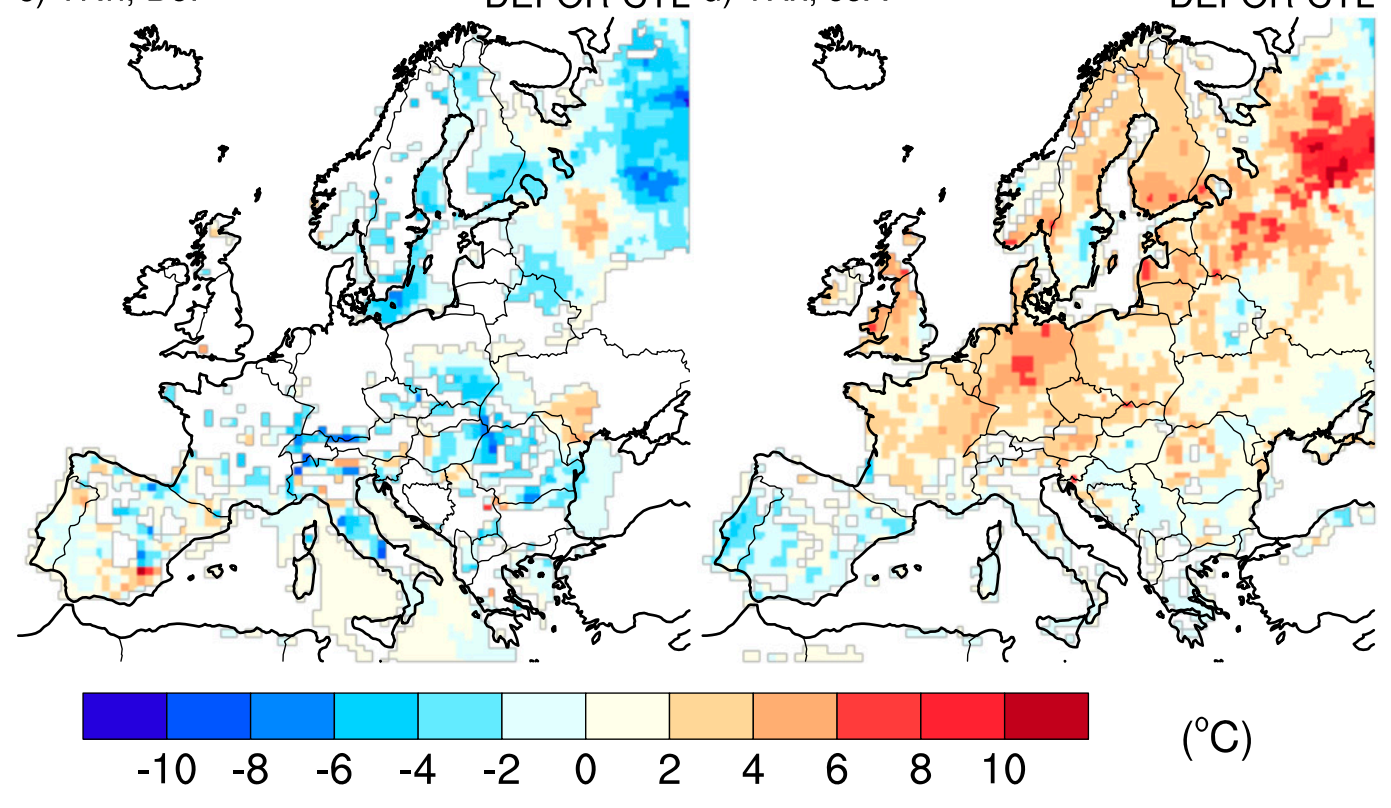

Figure 8. Difference in (left) winter minimum temperature (TNn; ${ }^{\circ} \mathrm{C}$ ) and (right) summer maximum temperature $\left(\mathrm{TXx} ;{ }^{\circ} \mathrm{C}\right)(\mathrm{a}),(\mathrm{b})$ between the AFFOR and CTL simulations and (c),(d) between the DEFOR and CTL simulations. Grid points that do not show statistically significant differences are omitted.

less variable in AFFOR than in CTL. An exception to this is dry regions in the far south where ET does not change much, even with afforestation.

Cold winter extremes (TNn) in DEFOR change in the same way as the winter mean temperature, but with somewhat larger differences in TNn in parts of central and eastern Europe (Figure 8c). This can be attributed to the combined effects of changes in outgoing longwave radiation and albedo, as described for AFFOR. Without trees, more of the incoming radiation is reflected, and less outgoing 
Earth Interactions - Volume 23 (2019) • Paper No. 1 • Page 15

radiation is captured by the vegetation and is instead released to space. In summer, deforestation exacerbates the difference in TXx in both directions; the increase in TXx is as much as $10^{\circ} \mathrm{C}$ in northeastern Europe and $2^{\circ}-6^{\circ} \mathrm{C}$ in most of continental Europe, as compared with $+2^{\circ}-3^{\circ} \mathrm{C}$ in Tmean (Figure 6d). Both the decrease in TXx over the Iberian Peninsula and the increase in the rest of Europe are larger than the differences in the mean temperature.

\subsection{The heat waves of August 2003 and July 2010}

To further investigate how land-use changes can ameliorate or exacerbate extreme temperatures, we take a look at the heat waves of August 2003 (centered over western Europe) and July 2010 (centered over eastern Europe), the top two European heat waves in 1981-2010 (Russo et al. 2015). First, the climatological 90th percentile of summer TX is calculated for every grid point over the period 19812010. Then, for August 2003 (AUG03) and July 2010 (JUL10), we calculate how many days in each grid box have a TX above the climatological 90th percentile; this number of exceedances is called TX90P. In a "normal" month, TX90P is around 3 (i.e., $10 \%$ of the days). In AUG03, the CTL simulation has a TX90P of 16-22 in a band over France, Germany, and Poland, meaning that at least one-half of the days of the month were extremely warm (Figure 9).

In AFFOR, summer temperatures are lower than in CTL (cf. Figures 6 and 8), and consequently, TX90P is lower (Figure 9b). The decrease in TX90P is about the same as the absolute value of TX90P in CTL; thus, the August 2003 heat wave is more or less completely mitigated in AFFOR (Figures 9a,b). DEFOR shows a strongly contrasting pattern and an even more pronounced heat wave in many areas. The largest increase in TX90P is outside the area of the CTL center of the heat wave, where the room for prolonging the heat wave is larger; most of central Europe gets a TX90P of more than 15 days (Figures 9a-c). Note that TX90P also decreases over the Iberian Peninsula in DEFOR, which agrees with the differences in Tmean and TXx (cf. Figures 6d and 8d).

In JUL10, the center of the heat wave was in eastern Europe, where TX90P reached over 16 days in large areas. In AFFOR, most of the heat waves disappear in the central and southern parts of the heat-wave area, and in DEFOR, the area of TX90P more than 15 days expands to the north and northeast (Figures 9d-f). That TX90P increases over Scandinavia in both AFFOR and DEFOR is unexpected. Since the difference in land cover is small between CTL and AFFOR over Scandinavia, we would expect a weaker response relative to between DEFOR and CTL. A possible explanation for differences in TX90P in areas with small differences in land cover may be changed atmospheric circulation. As shown above, afforestation affects circulation in all of Europe, which in turn affects the characteristics of specific events such as heat waves. A small displacement of a high pressure blocking can change the characteristics of a heat wave.

\subsection{Precipitation}

RCA4 shows only a few significant precipitation differences in AFFOR relative to CTL: around $10 \%$ less in winter, mainly in parts of western central Europe, and around $20 \%$ more in scattered parts of southern and central Europe in summer (Figures 10a,b). Also, a decrease of the maximum daily precipitation of $10 \%-20 \%$ is present in the 


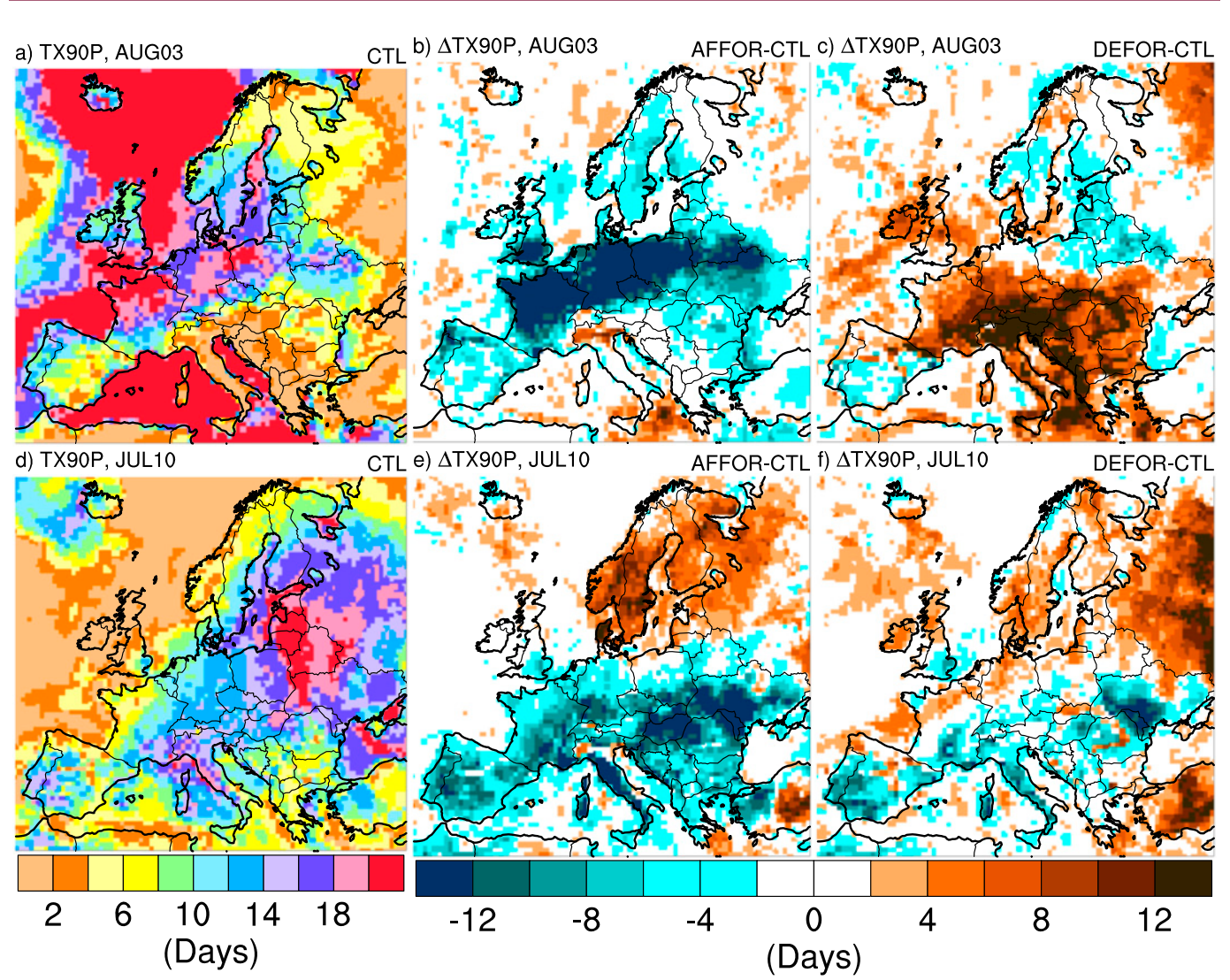

Figure 9. Number of days with temperature maximum above the 90th percentile (TX90P; days) in (a) August 2003 (AUG03) and (d) July 2010 (JUL10) in the CTL simulation. Also shown are the (b),(e) difference between the AFFOR and CTL simulations and (c),(f) difference between the DEFOR and CTL simulations.

areas of mean precipitation decrease (not shown). The differences in summer precipitation are mainly because of differences in convective precipitation, which is mostly determined by local ET (not shown). Precipitation differences in DEFOR are small relative to CTL for both mean and daily maximum precipitation and are statistically significant only over a few small scattered regions (Table 1; Figures 10c,d).

\subsection{Nonlocal effects}

In the simulations with vegetation changes in only half of the model domain, the results in the western part of the domain are very similar to those in AFFOR and DEFOR (Figure 11; cf. Figures 5 and 6). The eastern part of the domain is very similar to that in CTL in both simulations. There are some areas with statistically significant differences in ET in the east, but they are small, randomly scattered spatially, and possibly an effect of internal variability. In DEFOR, there is some increased ET just east of $15^{\circ} \mathrm{E}$ (Figure 11b). It is difficult to determine whether this is due to internal variability or is an actual response to the decreased ET in the vicinity. However, this difference in ET, random or not, has little effect on Tmean (Figure 11d). 


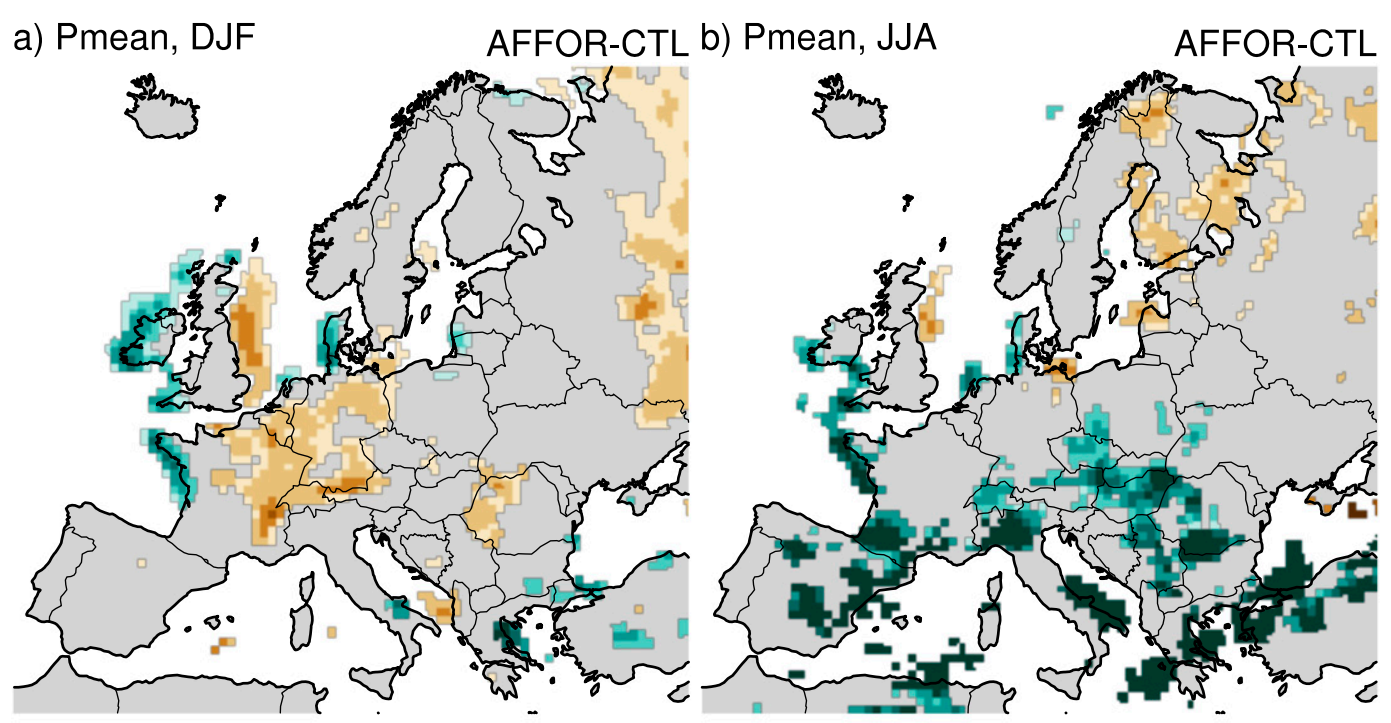

c) Pmean, DJF

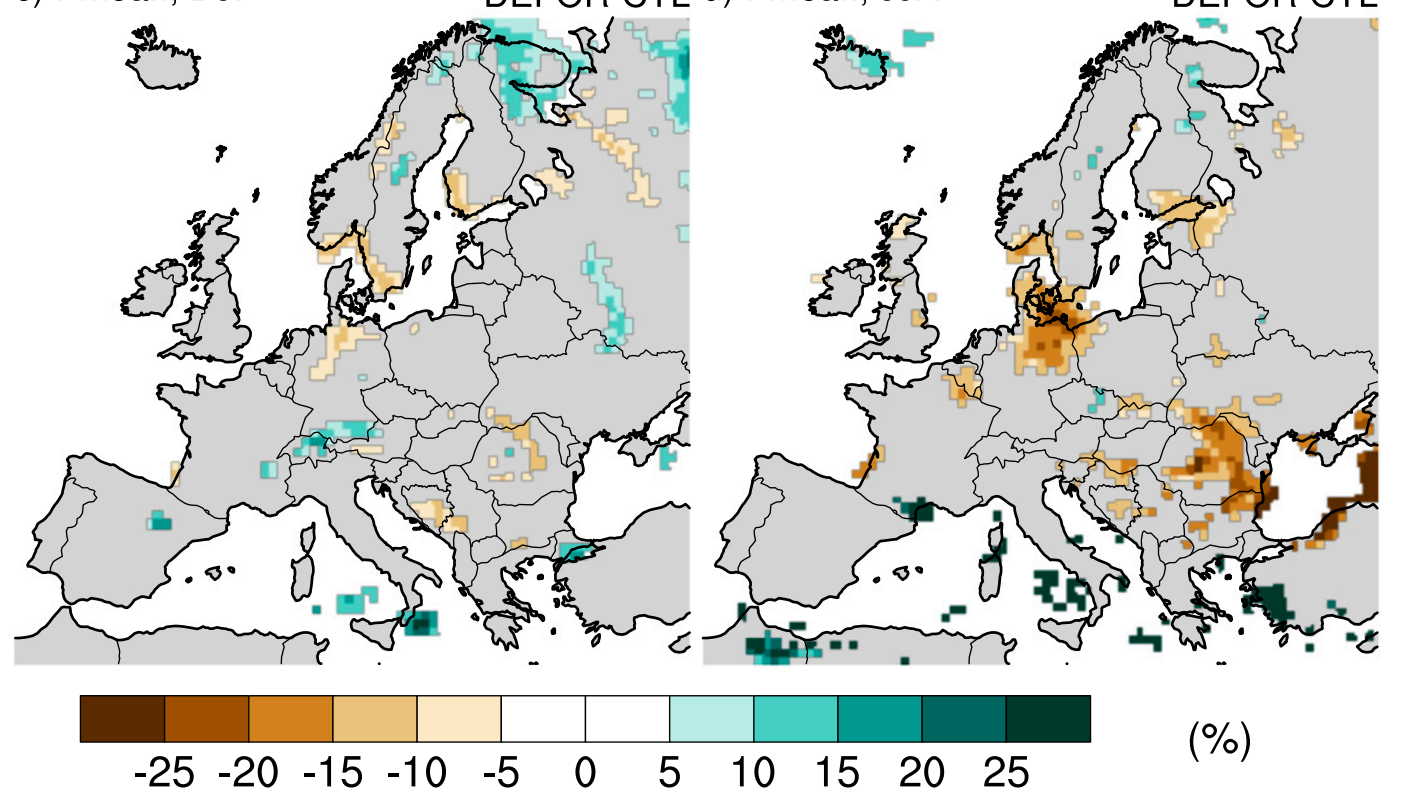

Figure 10. Difference in mean precipitation (Pmean; \%) (a),(b) between the AFFOR and CTL simulations and (c),(d) between the DEFOR and CTL simulations for (left) winter (DJF) and (right) summer (JJA). Grid points that do not show statistically significant differences are omitted.

\section{Discussion}

\subsection{What determines the response in climate to changes in land cover?}

This study estimates the potential response in climate due to maximum potential vegetation changes in Europe. It is clear that vegetation changes can have a significant impact on mean temperature that is of the same magnitude as the 
Earth Interactions • Volume 23 (2019) • Paper No. 1 • Page 18

Table 1. Percentage of grid points over land with significant difference in the AFFOR and DEFOR simulations relative to the CTL simulation.

\begin{tabular}{cccc}
\hline & Season & AFFOR & DEFOR \\
\hline \multirow{2}{*}{ Tmean } & DJF & $38 \%$ & $26 \%$ \\
& JJA & $64 \%$ & $57 \%$ \\
Pmean & DJF & $16 \%$ & $9 \%$ \\
& JJA & $16 \%$ & $8 \%$ \\
\hline
\end{tabular}

temperature changes resulting from the greenhouse-gas-driven external forcings. For example, Strandberg et al. (2015) show that changes in seasonal mean temperature over large parts of Europe are on the order of $1^{\circ}-3^{\circ} \mathrm{C}$ at the end of the century under the RCP2.6 scenario with changing greenhouse gases but constant land cover. This is similar to the warming that Europe would experience in a $2^{\circ} \mathrm{C}$ warmer world (e.g., Vautard et al. 2014; Kjellström et al. 2018). However, the differences seen here show a different geographic pattern as the vegetation-induced changes are more confined to the areas where vegetation changes as compared with the relatively more uniform greenhouse-gas signal. Our results show that the impact on extreme temperature is even larger; this is also in accord with Vautard et al. (2014). A decrease (increase) in mean temperature tends to be associated with an even larger decrease (increase) in extreme temperature. For example, in summer in southern Europe an increase in ET will decrease temperature; this effect is even stronger during the warmest days, which are usually connected with a lack of soil moisture. This asymmetric impact on temperature is seen in previous studies of observations, reanalyses, and climate models (e.g., Kjellström 2004; Seneviratne et al. 2013; Davin et al. 2014).

This study suggests that afforestation (deforestation) can help to exacerbate (ameliorate) heat waves. The analysis of two heat waves agrees overall with the mean climatological responses described in sections 4.2 and 4.3, but it also shows the difficulties of telling a counterfactual story of specific weather events if the land cover had been different. Afforestation has an impact on the large-scale atmospheric circulation over most of Europe. This means that synoptic events will not be exactly the same as in the CTL simulation. When evaluating the long-term climatological effects of land-cover changes, this is not a problem as this evaluation still shows the general climatic response to land-cover changes. In the case of specific events, such as for the two heat waves analyzed here, this analysis shows that it can be difficult to disentangle differences that are due to differences in biogeophysical effects and differences that are due to circulation changes.

Despite relatively large changes in ET and temperature, precipitation changes are generally small and confined to a few scattered regions. Previous studies likewise point to minor effects on seasonal mean precipitation (e.g., Roy et al. 2007; Quintanar and Mahmood 2012; Seneviratne et al. 2013; Winchester et al. 2017); however, comparison with observations suggests that climate models are not able to fully reproduce the soil-moisture precipitation feedback (Taylor et al. 2012), although it cannot be ruled out that this is because of the coarse resolution in the investigated global climate models. The current study suggests that these processes are local and may only be resolved at high horizontal model resolution. Possibly, even higher resolution - on the order of that of convective rain events-is needed to adequately capture these feedbacks in a realistic way; nevertheless, when comparing with observations, it is also unclear what feedback actually dominates 

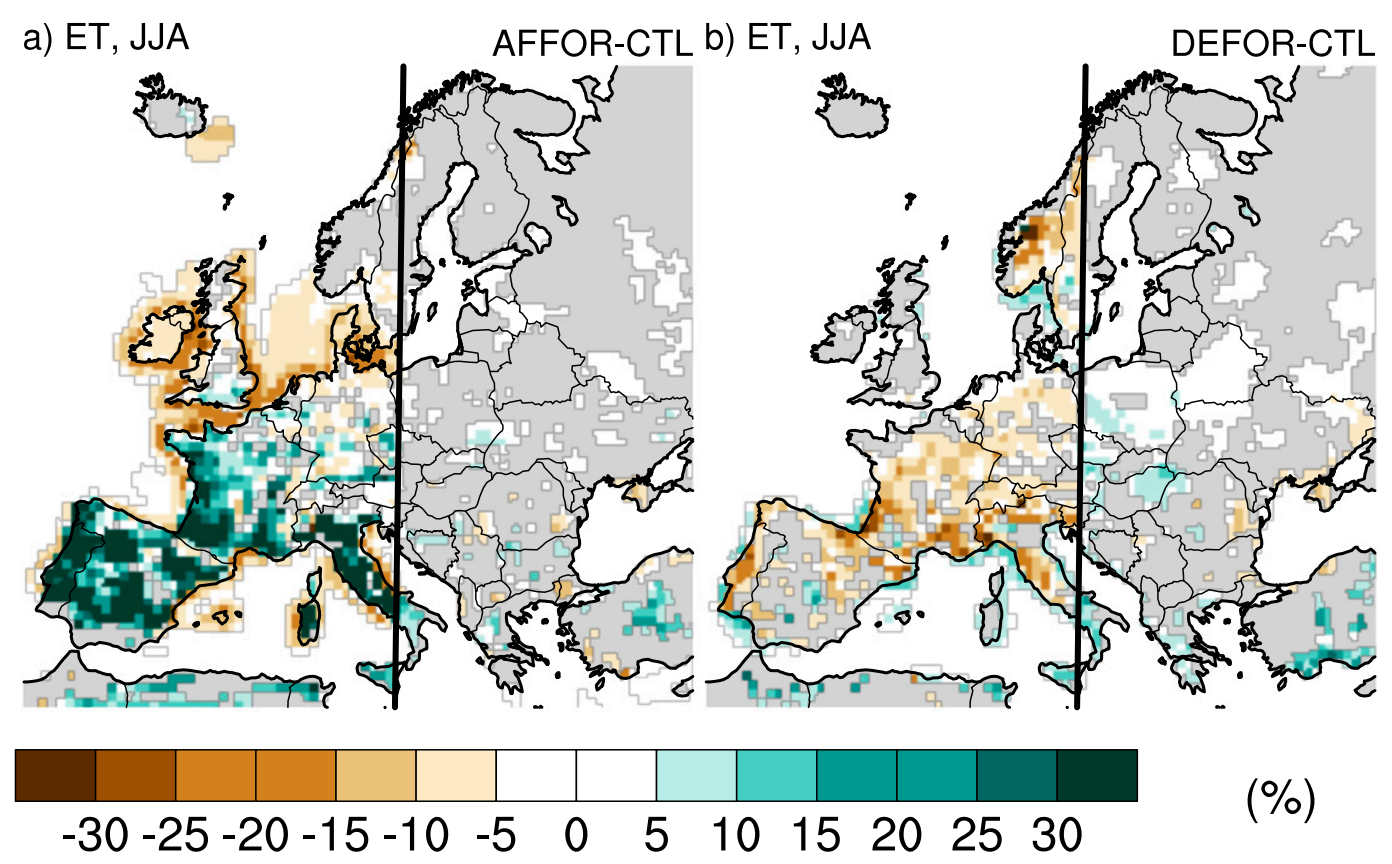

$(\%)$

c) Tmean, JJA
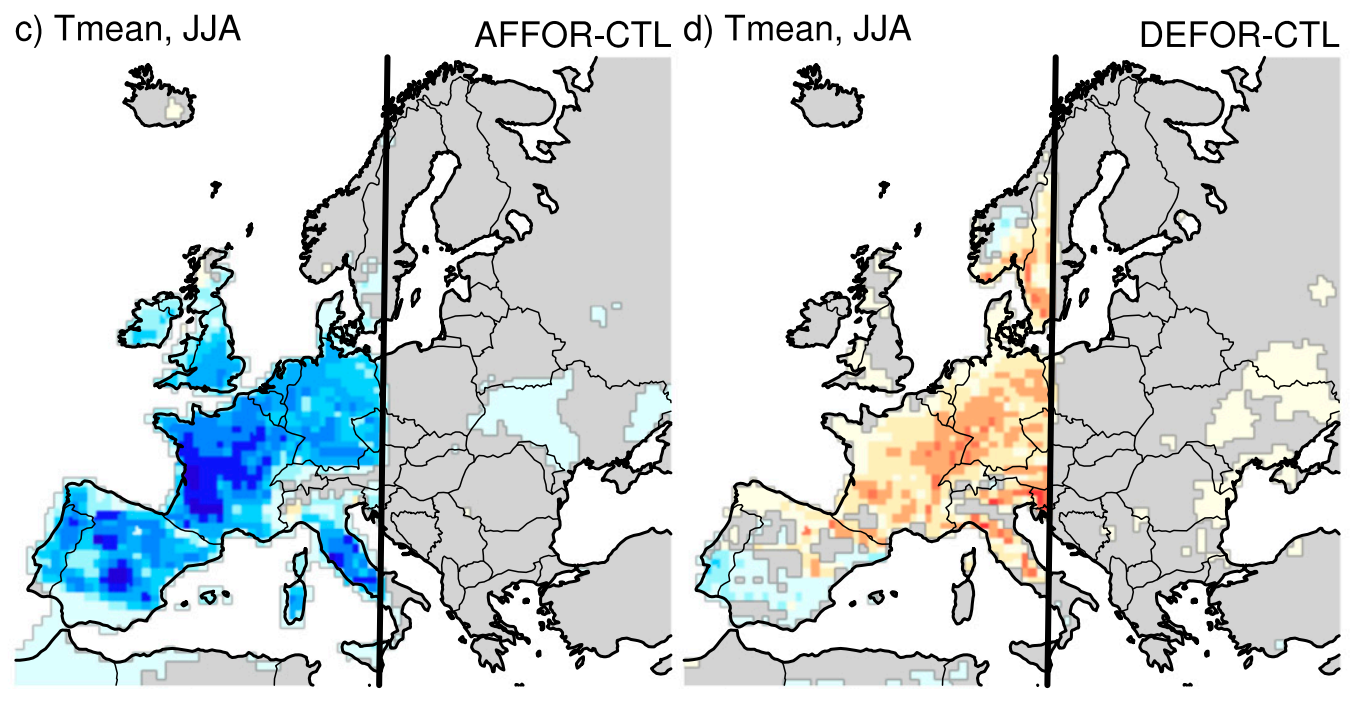

$$
\begin{array}{lllllllllllll}
-3 & -2.5 & -2 & -1.5 & -1 & -0.5 & 0 & 0.5 & 1 & 1.5 & 2 & 2.5 & 3
\end{array}
$$

Figure 11. Difference in summer (JJA) (a),(b) ET (\%) and (c), (d) Tmean ( $\left.{ }^{\circ} \mathrm{C}\right)$ (left) between the AFFOR, and CTL simulations and (right) between the DEFOR and CTL simulations. The vertical black line shows the division between changed and unchanged vegetation. Grid points that do not show statistically significant differences are omitted. 
Earth Interactions - Volume 23 (2019) • Paper No. 1 • Page 20

the process (Guillod et al. 2015). Afforestation affects how cyclones travel and evolve over Europe, with increased roughness generally reducing cyclone activity inland. Getting this effect, however, requires that large areas are afforested as compared with the more local albedo and ET effects that result from small-scale land-cover changes.

The interaction between vegetation and climate can mainly be attributed to two biogeophysical processes: albedo changes and changes in evapotranspiration. Which process dominates depends on regional characteristics such as length of snow season, amount of water available for evapotranspiration, and time of year. For Europe, our results show that winter evapotranspiration is small and thus albedo dominates, especially in regions where open snow-covered land with high albedo is replaced by dark forests (or the other way around). This kind of change in vegetation is possible in northern and northeastern Europe and in high-altitude regions in southern Europe. In summer, evapotranspiration is large enough to dominate the land-cover-related temperature feedbacks in most of the model domain. Exceptions to this are areas around the Mediterranean Sea, especially over the Iberian Peninsula, where summers are dry and soil moisture is depleted already in the spring (e.g., Räisänen et al. 2004). Our results agree with previous studies on afforestation leading to a cooling in summer as a result of increased evapotranspiration (e.g., Gálos et al. 2011; Gao et al. 2014; Stéfanon et al. 2014; Perugini et al. 2017). Typically, such cooling is around $1^{\circ} \mathrm{C}$ on a seasonal mean basis, whereas the effect is stronger for warm extremes (Stéfanon et al. 2014), as also found here. Similarly, our results are in agreement with previous studies showing that afforestation also leads to a warming in boreal regions in winter/spring (Gao et al. 2014; Perugini et al. 2017). The effect on precipitation is small and seemingly is not directly coupled to land-cover changes because precipitation to a large extent is controlled by large-scale meteorological conditions, which is a result in line with findings presented by Gálos et al. (2011), Gao et al. (2014), and Perugini et al. (2017). Zampieri and Lionello (2011) get the opposite result: summer temperatures are higher when crops are replaced by potential vegetation, but it is because crops in their experiment transpire more than trees. The contradictory results in their study are thus explained by differences in vegetation characteristics rather than by a different understanding of the physical mechanisms.

Some studies suggest that there are nonlocal effects, so-called teleconnections, on climate from vegetation changes, meaning that vegetation at one point will affect climate somewhere else. Teleconnections have been inferred for soilmoisture feedback on temperature (Seneviratne et al. 2013), evaporation feedback on precipitation in GCMs (Seneviratne et al. 2010; van der Ent and Savenije 2011), albedo feedback on temperature and snow cover in an RCM (Alexandru and Sushama 2016), and effects of tropical greening on circulation and rainfall patterns in an RCM (Wu et al. 2016). The simulations made in this study with vegetation changes in only one-half of the model domain show very small or no effect in the unchanged part. The conclusion is that there is no robust evidence for teleconnections given changes in a small area like one-half of Europe; this should be considered with the caveat that the simulations in this study use reanalysis boundary conditions and are not totally free to simulate their own atmospheric circulation. Further tests with global models of high resolution could be a way to explore possible nonlocal effects on climate from small-scale changes in land cover. 
Earth Interactions - Volume 23 (2019) • Paper No. 1 • Page 21

Last, it should be acknowledged that there are other possible land-cover changes besides afforestation and deforestation. In many parts of Europe, it is more likely that urban areas will spread at the expense of forests or agricultural land. Urbanization was not considered here, and for even finer-scale local studies it would be interesting to investigate the effects of different options in city planning (e.g., concrete vs green infrastructure).

\subsection{Implications for past climate change}

Even though the exact timing of the start of anthropogenic deforestation in Europe is debated (see, e.g., Gaillard et al. 2010), it is clear that the vegetation has gone from natural (potential) to the present highly anthropogenic conditions, with a forest fraction less than $30 \%$ in most parts of continental Europe during the last 1000-3000 years (e.g., Kaplan et al. 2009; Klein Goldewijk et al. 2011). The results of this study imply that past deforestation is expected to have had a significant impact on local climate across Europe. The difference in seasonal mean near-surface temperature between the simulation with potential vegetation and the simulation with present-day vegetation is $0^{\circ}-2^{\circ} \mathrm{C}$ in winter and $1^{\circ}-3^{\circ} \mathrm{C}$ in summer in central and southern Europe (Figures 6a,b). If we change the sign in Figures $6 \mathrm{a}$ and $6 \mathrm{~b}$, going from potential vegetation to present-day conditions, we see that the anthropogenic deforestation over the last 1000-3000 years could have led to a warming of $0^{\circ}-3^{\circ} \mathrm{C}$, depending on region and season. Most of this warming should have occurred during the last part of this period, when changes in land cover have been most substantial (e.g., Kaplan et al. 2009; Klein Goldewijk et al. 2011). That the climatic response to land-cover changes is small at $6000 \mathrm{yr} \mathrm{BP}$ relative to that at AD 1800 is supported by an earlier study with the RCA3 model (Strandberg et al. 2014). It should be a topic for future research to better constrain the timing and contribution of historical land-cover changes to past climate change. Furthermore, the results indicate that regional and local vegetation changes should be considered when interpreting past climate proxy records in Europe, so that local-scale changes are not misinterpreted as large-scale drivers. The results presented here, including the experiments in which large areas like one-half of Europe undergo a considerable shift in land cover, indicate that the biogeophysical effect primarily affects local climate.

\subsection{Implications for future climate change and for mitigation strategies}

The impact on future climate is, of course, dependent on what the actual future land use will be. There is great potential in using afforestation as a mitigation strategy for global warming since growing forests serve as sinks of $\mathrm{CO}_{2}$ (e.g., Smith et al. 2014), provided, of course, that $\mathrm{CO}_{2}$ is captured and sequestered. Our results show that afforestation would also be favorable to mitigate regional temperature increase as it leads to lower temperature locally (Figures 6a,b). At the same time, in stabilization and mitigation scenarios like RCP2.6, the demand for cropland is increasing as a result of bioenergy production (van Vuuren et al. 2007). This may lead to decreased levels of atmospheric $\mathrm{CO}_{2}$ if bioenergy replaces fossil fuels, which eventually will decrease global warming. Regionally, however, this 
Earth Interactions • Volume 23 (2019) - Paper No. 1 • Page 22

may lead to increased temperature if forests are replaced by agricultural land or land for bioenergy (Figures 6c,d), which may be an unwanted local effect of a global mitigation strategy. The exact response to these land-cover changes is not possible to determine in a general way since the response depends on regional characteristics; this should be considered when such mitigation strategies are planned. We show in this study that the response in climate to landcover changes varies over Europe; globally, the situation is even more complicated. Highly resolved Earth system models should be used to study the interplay among atmospheric greenhouse gases, radiative fluxes, and heat fluxes. Studies of the effect on radiative forcing from changes in land use are made (e.g., Jones et al. 2015); this should be pursued further, especially at higher model resolution.

\subsection{How can the biogeophysical forcing better be constrained?}

This study provides some suggestions, but the question remains as to what the net effect of land-cover changes on climate is. The effect in the model simulation is, of course, dependent on the model itself and is not proven to be robust until it is reproduced by other models. Ways to better constrain the biogeophysical forcing could be obtained through model intercomparison studies that involve coordinated simulations with an ensemble of climate models, through more land surface model simulations, and through more observations (e.g., of heat fluxes and soil moisture).

\section{Conclusions}

This study demonstrates that the local effect on climate from maximum afforestation and deforestation is comparable in magnitude to the effect from greenhouse gas forcing in the future. Complete afforestation of all unforested areas in Europe leads to a general cooling of $0.5^{\circ}-3^{\circ} \mathrm{C}$ in all seasons. The largest differences are seen in summer in areas of large vegetation change in southern Europe. Complete deforestation of all forested areas leads to a general warming in summer of $0.5^{\circ}-2.5^{\circ} \mathrm{C}$. An exception to this is the Iberian Peninsula, where some regions show a cooling. In winter, the differences are smaller and of different signs: cooling in the northeast of around $1{ }^{\circ} \mathrm{C}$ and warming in the southwest of around $0.5^{\circ} \mathrm{C}$. The effect on maximum and minimum temperature is stronger than on the mean temperature. The temperature differences are controlled by differences in albedo and evapotranspiration. Albedo tends to dominate in winter and evapotranspiration in summer. There are exceptions to this (such as the Iberian Peninsula); if there is no water available for evapotranspiration, changes in vegetation will not lead to differences in evapotranspiration. In this case, albedo will control temperature differences in summer also. The effect on precipitation is less certain. There are regions with significant precipitation differences, and increased (decreased) precipitation corresponds to increased (decreased) ET, but there are regions with significant differences in ET without significant differences in precipitation. The climatic effects from changed vegetation are local. In our 50-km-resolution simulations, we detected no evidence that vegetation changes in one area should directly affect the climate in other regions; however, the results suggest that large-scale land-cover changes affect the large-scale atmospheric circulation, even though it is unclear whether these changes have an impact on the climate over 30 years. 
Our simulations imply that vegetation-climate interactions are important to understand past and future climate change and should be included in climate model simulations. The results presented here are in general agreement with previous models and observations in how the biogeophysical effects work and how they may be affected by land-cover changes, and we further provide the maximum effect of both afforestation and deforestation, which has not previously been done at the regional scale.

Acknowledgments. This study was partly funded by a research project financed by the Swedish Research Council VR (Vetenskapsrådet) on "Quantification of the biogeophysical and biogeochemical forcings from anthropogenic deforestation on regional Holocene climate in Europe, LandClim II." All model simulations were performed on the Swedish climate computing resource $\mathrm{Bi}$ and other resources provided by the Swedish National Infrastructure for Computing (SNIC) at the Swedish National Supercomputing Centre (NSC) at Linköping University. The authors thank Patrick Samuelsson for help with setting up RCA4. Heiner Körnich, Anders Moberg, Ben Smith, and Qiong Zhang commented on earlier versions of the paper.

\section{References}

Alexandru, A., and L. Sushama, 2016: Impact of land-use and land-cover changes on CRCM5 climate projections over North America for the twenty-first century. Climate Dyn., 47, 11971209, https://doi.org/10.1007/s00382-015-2896-3.

Andrews, T., R. A. Betts, B. B. B. Booth, C. D. Jones, and G. Jones, 2017: Effective radiative forcing from historical land use change. Climate Dyn., 48, 3489-3505, https://doi.org/ 10.1007/s00382-016-3280-7

Arneth, A., and Coauthors, 2010: Terrestrial biogeochemical feedbacks in the climate system. Nat. Geosci., 3, 525-532, https://doi.org/10.1038/ngeo905.

Avila, F. B., A. J. Pitman, M. G. Donat, L. V. Alexander, and G. Abramowitz, 2012: Climate model simulated changes in temperature extremes due to land cover change. J. Geophys. Res., 117, D04108, https://doi.org/10.1029/2011JD016382.

Bala, G., K. Caldeira, M. Wickett, T. J. Phillips, D. B. Lobell, C. Delire, and A. Mirin, 2007: Combined climate and carbon-cycle effects of large-scale deforestation. Proc. Natl. Acad. Sci. USA, 104, 6550-6555, https://doi.org/10.1073/pnas.0608998104.

Bathiany, S., M. Claussen, V. Brovkin, T. Raddatz, and V. Gayler, 2010: Combined biogeophysical and biogeochemical effects of large-scale forest cover changes in the MPI earth system model. Biogeosciences, 7, 1383-1399, https://doi.org/10.5194/bg-7-1383-2010.

Betts, R. A., P. D. Falloon, K. Klein Goldewijk, and N. Ramankutty, 2007: Biogeophysical effects of land use on climate: Model simulations of radiative forcing and large-scale temperature change. Agric. For. Meteor., 142, 216-233, https://doi.org/10.1016/j.agrformet.2006.08.021.

Brovkin, V., and Coauthors, 2006: Biogeophysical effects of historical land cover changes simulated by six Earth system models of intermediate complexity. Climate Dyn., 26, 587-600, https://doi.org/10.1007/s00382-005-0092-6.

— , and Coauthors, 2013: Effect of anthropogenic land-use and land-cover changes on climate and land carbon storage in CMIP5 projections for the twenty-first century. J. Climate, 26, 6859-6881, https://doi.org/10.1175/JCLI-D-12-00623.1.

Carter, T. R., and Coauthors, 2007: New assessment methods and the characterization of future conditions. Climate Change 2007: Impacts, Adaptation and Vulnerability, M. L. Parry et al., Eds., Cambridge University Press, 133-171.

Champeaux, J. L., V. Masson, and F. Chauvin, 2005: ECOCLIMAP: A global database of land surface parameters at $1 \mathrm{~km}$ resolution. Meteor. Appl., 12, 29-32, https://doi.org/10.1017/ S1350482705001519. 


\section{Earth Interactions • Volume 23 (2019) • Paper No. 1 • Page 24}

Christidis, N., P. A. Stott, G. C. Hegerl, and R. A. Betts, 2013: The role of land use change in the recent warming of daily extreme temperatures. Geophys. Res. Lett., 40, 589-594, https://doi. org/10.1002/grl.50159.

Cubasch, U., D. Wuebbles, D. Chen, M. C. Facchini, D. Frame, N. Mahowald, and J.-G. Winther, 2013: Introduction. Climate Change 2013: The Physical Science Basis, T. F. Stocker et al., Eds., Cambridge University Press, 119-158, https://www.ipcc.ch/site/assets/uploads/2017/ 09/WG1AR5_Chapter01_FINAL.pdf.

Davin, E. L., S. I. Seneviratne, P. Ciais, A. Olioso, and T. Wang, 2014: Preferential cooling of hot extremes from cropland albedo management. Proc. Natl. Acad. Sci. USA, 111, 9757-9761, https://doi.org/10.1073/pnas.1317323111.

Dee, D. P., and Coauthors, 2011: The ERA-Interim reanalysis: Configuration and performance of the data assimilation system. Quart. J. Roy. Meteor. Soc., 137, 553-597, https://doi.org/ 10.1002/qj.828.

Findell, K. L., E. Shevliakova, P. C. D. Milly, and R. J. Stouffer, 2007: Modeled impact of anthropogenic land cover change on climate. J. Climate, 20, 3621-3634, https://doi.org/ 10.1175/JCLI4185.1.

— A. J. Pitman, M. H. England, and P. J. Pegion, 2009: Regional and global impacts of land cover change and sea surface temperature anomalies. J. Climate, 22, 3248-3269, https://doi. org/10.1175/2008JCLI2580.1.

Forster, P., and Coauthors, 2007: Changes in atmospheric constituents and in radiative forcing. Climate Change 2007: The Physical Science Basis, S. Solomon et al., Eds., Cambridge University Press, 129-234, https://www.ipcc.ch/site/assets/uploads/2018/02/ar4-wg1-chapter2-1.pdf.

Gaillard, M.-J., and Coauthors, 2010: Holocene land-cover reconstructions for studies on land cover-climate feedbacks. Climate Past, 6, 483-499, https://doi.org/10.5194/cp-6-483-2010.

Gálos, B., C. Mátyás, and D. Jacob, 2011: Regional characteristics of climate change altering effects of afforestation. Environ. Res. Lett., 6, 044010, https://doi.org/10.1088/1748-9326/6/ 4/044010.

- A. Hänsler, G. Kindermann, D. Rechid, K. Sieck, and D. Jacob, 2012: The role of forests in mitigating climate change-A case study for Europe. Acta Silv. Lign. Hung., 8, 87-102, https://doi.org/10.2478/v10303-012-0007-2.

Gao, Y., T. Markkanen, L. Backman, H. M. Henttonen, J.-P. Pietikäinen, H. M. Mäkelä, and A. Laaksonen, 2014: Biogeophysical impacts of peatland forestation on regional climate changes in Finland. Biogeosciences, 11, 7251-7267, https://doi.org/10.5194/bg-11-7251-2014.

Goosse, H., J. Guiot, M. E. Mann, S. Dubinkina, and Y. Sallaz-Damaz, 2012: The medieval climate anomaly in Europe: Comparison of the summer and annual mean signals in two reconstructions and in simulations with data assimilation. Global Planet. Change, 84-85, 35-47, https://doi.org/10.1016/j.gloplacha.2011.07.002.

Graham, L. P., J. Olsson, E. Kjellström, J. Rosberg, S.-S. Hellström, and R. Berndtsson, 2009: Simulating river flow to the Baltic Sea from climate simulations over the past millennium. Boreal Environ. Res., 14, 173-182.

Guillod, B. P., B. Orlowsky, D. G. Miralles, A. J. Teuling, and S. I. Seneviratne, 2015: Reconciling spatial and temporal soil moisture effects on afternoon rainfall. Nat. Comm., 6, 6443, https:// doi.org/10.1038/ncomms7443.

He, F., S. J. Vavrus, J. E. Kutzbach, W. F. Ruddiman, J. O. Kaplan, and K. M. Krumhardt, 2014: Simulating global and local surface temperature changes due to Holocene anthropogenic land cover change. Geophys. Res. Lett., 41, 623-631, https://doi.org/10.1002/2013GL058085.

Hickler, T., B. Smith, M. T. Sykes, M. B. Davis, S. Sugita, and K. Walker, 2004: Using a generalized vegetation model to simulate vegetation dynamics in northeastern USA. Ecology, 85, 519530, https://doi.org/10.1890/02-0344.

— tation zones with a generalized, tree species-based dynamic vegetation model. Global Ecol. Biogeogr., 21, 50-63, https://doi.org/10.1111/j.1466-8238.2010.00613.x. 


\section{Earth Interactions • Volume 23 (2019) • Paper No. 1 • Page 25}

Jahn, A., M. Claussen, A. Ganopolski, and V. Brovkin, 2005: Quantifying the effect of vegetation dynamics on the climate of the Last Glacial Maximum. Climate Past, 1, 1-7, https://doi.org/ 10.5194/cp-1-1-2005.

Jarvis, P. G., J. L. Monteith, and P. E. Weatherley, 1976: The interpretation of the variations in leaf water potential and stomatal conductance found in canopies in the field. Philos. Trans. Roy. Soc. London, 273B, 593-610, https://doi.org/10.1098/rstb.1976.0035.

Jones, A. D., K. V. Calvin, W. D. Collins, and J. Edmonds, 2015: Accounting for radiative forcing from albedo change in future global land-use scenarios. Climatic Change, 131, 691-703, https://doi.org/10.1007/s10584-015-1411-5.

Kaplan, J., K. Krumhardt, and N. Zimmermann, 2009: The prehistoric and preindustrial deforestation of Europe. Quat. Sci. Rev., 28, 3016-3034, https://doi.org/10.1016/j.quascirev.2009.09.028.

Kelliher, F. M., R. Leuning, and E.-D. Schulze, 1993: Evaporation and canopy characteristics of coniferous forests and grasslands. Oecologia, 95, 153-163, https://doi.org/10.1007/ BF00323485.

Keys, P. W., L. Wang-Erlandsson, and L. J. Gordon, 2016: Revealing invisible water: Moisture recycling as an ecosystem service. PLOS ONE, 11, e0151993, https://doi.org/10.1371/journal.pone.0151993.

Kjellström, E., 2004: Recent and future signatures of climate change in Europe. Ambio, 33, 193 199, https://doi.org/10.1579/0044-7447-33.4.193.

— , J. Brandefelt, J. O. Näslund, B. Smith, G. Strandberg, A. H. L. Voelker, and B. Wohlfarth, 2010: Simulated climate conditions in Fennoscandia during a MIS 3 stadial. Boreas, 39, 436456, https://doi.org/10.1111/j.1502-3885.2010.00143.x.

, G. Nikulin, U. Hansson, G. Strandberg, and A. Ullerstig, 2011: 21st century changes in the European climate: Uncertainties derived from an ensemble of regional climate model simulations. Tellus, 63A, 24-40, https://doi.org/10.1111/j.1600-0870.2010.00475.x.

— _ L. Bärring, G. Nikulin, C. Nilsson, G. Persson, and G. Strandberg, 2016: Production and use of regional climate model projections-A Swedish perspective on building climate services. Climate Serv., 2-3, 15-29, https://doi.org/10.1016/j.cliser.2016.06.004.

- , and Coauthors, 2018: European climate change at global mean temperature increases of 1.5 and $2{ }^{\circ} \mathrm{C}$ above pre-industrial conditions as simulated by the EURO-CORDEX regional climate models. Earth Syst. Dyn., 9, 459-478, https://doi.org/10.5194/esd-9-459-2018.

Kleidon, A., K. Fraedrich, and M. Heimann, 2000: A green planet versus a desert world: Estimating the maximum effect of vegetation on the land surface climate. Climatic Change, 44, 471-493, https://doi.org/10.1023/A:1005559518889.

Klein Goldewijk, K., A. Beusen, M. de Vos, and G. van Drecht, 2011: The HYDE 3.1 spatially explicit database of human-induced global land-use change over the past 12,000 years. Global Ecol. Biogeogr., 20, 73-86, https://doi.org/10.1111/j.1466-8238.2010.00587.x.

Levis, S., 2010: Modeling vegetation and land use in models of the Earth system. Wiley Interdiscip. Rev.: Climate Change, 1, 840-856, https://doi.org/10.1002/wcc.83.

McIlveen, R., 1992: Fundamentals of Weather and Climate. Chapman and Hall, 500 pp.

Myhre, G., and Coauthors, 2013: Anthropogenic and natural radiative forcing. Climate Change 2013: The Physical Science Basis, T. F. Stocker et al., Eds., Cambridge University Press, 659740, https://www.ipcc.ch/site/assets/uploads/2018/02/WG1AR5_Chapter08_FINAL.pdf.

Mykleby, P. M., P. K. Snyder, and T. E. Twine, 2017: Quantifying the trade-off between carbon sequestration and albedo in midlatitude and high-latitude North American forests. Geophys. Res. Lett., 44, 2493-2501, https://doi.org/10.1002/2016GL071459.

Nikulin, G., E. Kjellström, U. Hansson, G. Strandberg, and A. Ullerstig, 2011: Evaluation and future projections of temperature, precipitation and wind extremes over Europe in an ensemble of regional climate simulations. Tellus, 63A, 41-55, https://doi.org/10.1111/ j.1600-0870.2010.00466.x.

Perugini, L., L. Caporaso, S. Marconi, A. Cescatti, B. Quesada, N. de Noblet-Ducoudré, J. I. House, and A. Arneth, 2017: Biophysical effects on temperature and precipitation due to land cover change. Environ. Res. Lett., 12, 053002, https://doi.org/10.1088/1748-9326/aa6b3f. 


\section{Earth Interactions • Volume 23 (2019) • Paper No. 1 • Page 26}

Pielke, R. A., Sr., R. Avissar, M. Raupach, A. J. Dolman, X. Zeng, and A. S. Denning, 1998: Interactions between the atmosphere and terrestrial ecosystems: Influence on weather and climate. Global Change Biol., 4, 461-475, https://doi.org/10.1046/j.1365-2486.1998.t01-1-00176.x.

Pinto, E., Y. Shin, S. A. Cowling, and C. D. Jones, 2009: Past, present and future vegetation-cloud feedbacks in the Amazon Basin. Climate Dyn., 32, 741-751, https://doi.org/10.1007/s00382-009-0536-5.

Pitman, A. J., and Coauthors, 2009: Uncertainties in climate responses to past land cover change: First results from the LUCID intercomparison study. Geophys. Res. Lett., 36, L14814, https:// doi.org/10.1029/2009GL039076.

Pongratz, J., T. Raddatz, C. H. Reick, M. Esch, and M. Claussen, 2009: Radiative forcing from anthropogenic land cover change since A.D. 800. Geophys. Res. Lett., 36, L02709, https://doi. org/10.1029/2008GL036394.

Quintanar, A., and R. Mahmood, 2012: Ensemble forecast spread induced by soil moisture changes over mid-south and neighbouring mid-western region of the USA. Tellus, 64A, 17156, https:// doi.org/10.3402/tellusa.v64i0.17156.

Räisänen, J., and Coauthors, 2004: European climate in the late twenty-first century: Regional simulations with two driving global models and two forcing scenarios. Climate Dyn., 22, 1331, https://doi.org/10.1007/s00382-003-0365-x.

Roy, S. S., R. Mahmood, D. Niyogi, M. Lei, S. A. Foster, K. G. Hubbard, E. Douglas, and R. Pielke Sr., 2007: Impacts of the agricultural Green Revolution-induced land use changes on air temperatures in India. J. Geophys. Res., 112, D21108, https://doi.org/10.1029/2007JD008834.

Rummukainen, M., 2010: State-of-the-art with regional climate models. Wiley Interdiscip. Rev.: Climate Change, 1, 82-96, https://doi.org/10.1002/wcc.8.

—, J. Räisänen, B. Bringfelt, A. Ullerstig, A. Omstedt, U. Willén, U. Hansson, and C. Jones, 2001: A regional climate model for northern Europe: Model description and results from the downscaling of two GCM control simulations. Climate Dyn., 17, 339-359, https://doi.org/ $10.1007 / \mathrm{s} 003820000109$.

Russo, S., J. Sillmann, and E. M. Fischer, 2015: Top ten European heatwaves since 1950 and their occurrence in the coming decades. Environ. Res. Lett., 10, 124003, https://doi.org/10.1088/ 1748-9326/10/12/124003.

Samuelsson, P., and Coauthors, 2011: The Rossby Centre Regional Climate model RCA3: Model description and performance, Tellus, 63A, 4-23, https://doi.org/10.1111/j.1600-0870.2010.00478.x.

Schimanke, S., H. E. M. Meier, E. Kjellström, G. Strandberg, and R. Hordoir, 2012: The climate in the Baltic Sea region during the last millennium simulated with a regional climate model. Climate Past, 8, 1419-1433, https://doi.org/10.5194/cp-8-1419-2012.

Seneviratne, S. I., T. Corti, E. L. Davin, M. Hirschi, E. B. Jaeger, I. Lehner, B. Orlowsky, and A. J. Teuling, 2010: Investigating soil moisture-climate interactions in a changing climate: A review. Earth-Sci. Rev., 99, 125-161, https://doi.org/10.1016/j.earscirev.2010.02.004.

— and Coauthors, 2013: Impact of soil moisture-climate feedbacks on CMIP5 projections: First results from the GLACE-CMIP5 experiment. Geophys. Res. Lett., 40, 5212-5217, https://doi. org/10.1002/grl.50956.

Smith, B., I. C. Prentice, and M. T. Sykes, 2001: Representation of vegetation dynamics in the modelling of terrestrial ecosystems: Comparing two contrasting approaches within European climate space. Global Ecol. Biogeogr., 10, 621-637, https://doi.org/10.1046/j.1466-822X.2001.00256.x.

Smith, P., and Coauthors, 2014: Agriculture, forestry and other land use (AFOLU). Climate Change 2014: Mitigation of Climate Change, O. Edenhofer et al., Eds., Cambridge University Press, 811-922, https://www.ipcc.ch/site/assets/uploads/2018/02/ipcc_wg3_ar5_chapter11.pdf.

Stéfanon, M., S. Schindler, P. Drobinski, N. de Noblet-Ducoudré, and F. D’Andrea, 2014: Simulating the effect of anthropogenic vegetation land cover on heatwave temperatures over central France. Climate Res., 60, 133-146, https://doi.org/10.3354/cr01230.

Strandberg, G., J. Brandefelt, E. Kjellström, and B. Smith, 2011: High-resolution regional simulation of the last glacial maximum climate in Europe. Tellus, 63A, 107-125, https://doi.org/ 10.1111/j.1600-0870.2010.00485.x. 


\section{Earth Interactions • Volume 23 (2019) • Paper No. 1 - Page 27}

, and Coauthors, 2014: Regional climate model simulations for Europe at 6 and $0.2 \mathrm{k} \mathrm{BP}$ : Sensitivity to changes in anthropogenic deforestation. Climate Past, 10, 661-680, https:// doi.org/10.5194/cp-10-661-2014.

— - and Coauthors, 2015: CORDEX scenarios for Europe from the Rossby Centre regional climate model RCA4. SMHI Meteorology and Climatology Rep. 116, 84 pp., https://www. smhi.se/polopoly_fs/1.90275!/Menu/general/extGroup/attachmentColHold/mainCol1/file/ RMK_116.pdf.

Taylor, C. M., R. A. M. de Jeu, F. Guichard, P. P. Harris, and W. A. Dorigo, 2012: Afternoon rain more likely over drier soils. Nature, 489, 423-426, https://doi.org/10.1038/nature11377.

Teuling, A. J., and Coauthors, 2010: Contrasting response of European forest and grassland energy exchange to heatwaves. Nat. Geosci., 3, 722-727, https://doi.org/10.1038/ngeo950.

Trondman, A. K., and Coauthors, 2015: Pollen-based quantitative reconstructions of Holocene regional vegetation cover (plant-functional types and land-cover types) in Europe suitable for climate modelling. Global Change Biol., 21, 676-697, https://doi.org/10.1111/gcb.12737.

van der Ent, R. J., and H. H. G. Savenije, 2011: Length and time scales of atmospheric moisture recycling. Atmos. Chem. Phys., 11, 1853-1863, https://doi.org/10.5194/acp-11-1853-2011.

van Vuuren, D. P., M. J. G. den Elzen, P. L. Lucas, B. Eickhout, B. J. Strengers, B. van Ruijven, S. Wonink, and R. van Houdt, 2007: Stabilizing greenhouse gas concentrations at low levels: An assessment of reduction strategies and costs. Climatic Change, 81, 119-159, https://doi.org/ 10.1007/s10584-006-9172-9.

Vautard, R., and Coauthors, 2014: The European climate under a $2^{\circ} \mathrm{C}$ global warming. Environ. Res. Lett., 9, 034006, https://doi.org/10.1088/1748-9326/9/3/034006.

Winchester, J., R. Mahmood, W. Rodgers, F. Hossain, E. Rappin, J. Durkee, and T. Chronis, 2017: A model-based assessment of potential impacts of man-made reservoirs on precipitation. Earth Interact., 21, https://doi.org/10.1175/EI-D-16-0016.1.

Wramneby, A., B. Smith, and P. Samuelsson, 2010: Hot spots of vegetation-climate feedbacks under future greenhouse forcing in Europe. J. Geophys. Res., 115, D21119, https://doi.org/ 10.1029/2010JD014307.

Wu, M., G. Schurgers, M. Rummukainen, B. Smith, P. Samuelsson, C. Jansson, J. Siltberg, and W. May, 2016: Vegetation-climate feedbacks modulate rainfall patterns in Africa under future climate change. Earth Syst. Dyn., 7, 627-647, https://doi.org/10.5194/esd-7-627-2016.

,-- A. Ahlström, M. Rummukainen, P. Miller, B. Smith, and W. May, 2017: Impacts of land use on climate and ecosystem productivity over the Amazon and the South American continent. Environ. Res. Lett., 12, 054016, https://doi.org/10.1088/1748-9326/aa6fd6.

Zampieri, M., and P. Lionello, 2011: Anthropic land use causes summer cooling in central Europe. Climate Res., 46, 255-268, https://doi.org/10.3354/cr00981.

Earth Interactions is published jointly by the American Meteorological Society, the American Geophysical Union, and the Association of American Geographers. For information regarding reuse of this content and general copyright information, consult the AMS Copyright Policy (www.ametsoc.org/PUBSReuseLicenses). 